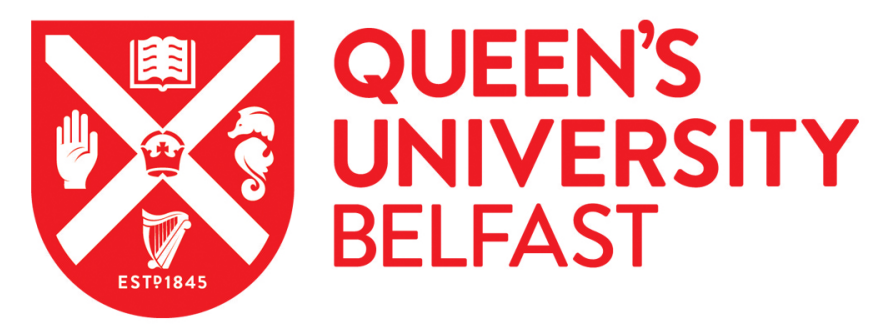

\title{
A central role for monocyte-platelet interactions in heart failure
}

Glezeva, N., Gilmer, J. F., Watson, C. J., \& Ledwidge, M. (2016). A central role for monocyte-platelet interactions in heart failure. Journal of Cardiovascular Pharmacology and Therapeutics, 21(3), 245-261. https://doi.org/10.1177/1074248415609436

Published in:

Journal of Cardiovascular Pharmacology and Therapeutics

Document Version:

Peer reviewed version

Queen's University Belfast - Research Portal:

Link to publication record in Queen's University Belfast Research Portal

Publisher rights

Copyright 2016 The Authors.

This work is made available online in accordance with the publisher's policies. Please refer to any applicable terms of use of the publisher.

\section{General rights}

Copyright for the publications made accessible via the Queen's University Belfast Research Portal is retained by the author(s) and / or other copyright owners and it is a condition of accessing these publications that users recognise and abide by the legal requirements associated with these rights.

Take down policy

The Research Portal is Queen's institutional repository that provides access to Queen's research output. Every effort has been made to ensure that content in the Research Portal does not infringe any person's rights, or applicable UK laws. If you discover content in the Research Portal that you believe breaches copyright or violates any law, please contact openaccess@qub.ac.uk. 


\section{A central role for Monocyte - Platelet Interactions in Heart Failure}

Nadezhda Glezeva ${ }^{{ }^{*}}$, John F. Gilmer ${ }^{2}$, Chris J. Watson ${ }^{1}$, Mark Ledwidge ${ }^{3}$

${ }^{1}$ School of Medicine \& Medical Science, UCD Conway Institute, University College Dublin, Dublin, Belfield, Dublin 4, Ireland

${ }^{2}$ School of Pharmacy \& Pharmaceutical Sciences TCD Centre for Health Sciences, Trinity College Dublin, College Green, Dublin, Ireland

${ }^{3}$ Chronic Cardiovascular Disease Management Unit and Heart Failure Unit, St Vincent's Healthcare Group/St Michael’s Hospital, Co. Dublin, Ireland.

\section{* Corresponding author:}

Nadezhda Glezeva

University College Dublin

Conway Institute of Biomolecular and Biomedical Research

Belfield, Dublin 4, Ireland

E-mail: nadezhda.glezeva@ucd.ie

Tel: +353 17166711

Fax: +353 17166701

\section{Conflict of interest}

Drs. Ledwidge and Gilmer report board membership and shares in Solvotrin Therapeutics and are named inventors on several patents relating to isosorbide prodrugs of aspirin. 


\begin{abstract}
Heart Failure (HF) is an increasingly prevalent and costly multifactorial syndrome with high morbidity and mortality rates. The exact pathophysiological mechanisms leading to the development of HF are not completely understood. Several emerging paradigms implicate cardio-metabolic risk factors, inflammation, endothelial dysfunction, myocardial fibrosis, and myocyte dysfunction as key factors in the gradual progression from a healthy state to HF. Inflammation is now a recognized factor in disease progression in HF and a therapeutic target. Furthermore, the monocyte - platelet interaction has been highlighted as an important pathophysiological link between inflammation, thrombosis, endothelial activation, and myocardial malfunction. The contribution of monocytes and platelets to acute cardiovascular injury and acute HF is well established. However their role and interaction in the pathogenesis of chronic HF is not well understood. In particular, the crosstalk between monocytes and platelets in the peripheral circulation and in the vicinity of the vascular wall in the form of monocyte - platelet complexes may be a crucial element, which influences the pathophysiology and progression of chronic heart disease and HF. In this review, we discuss the role of monocytes and platelets as key mediators of cardiovascular inflammation in HF, the mechanisms of cell activation, and the importance of monocyte-platelet interaction and complexes in HF pathogenesis. Finally, we summarize recent information on pharmacological inhibition of inflammation and studies of anti-thrombotic strategies in the setting of HF that can inform opportunities for future work. We discuss recent data on monocyte - platelet interactions and the potential benefits of therapy directed at monocyteplatelet complexes, particularly in the setting of HF with preserved ejection fraction.
\end{abstract}




\section{Keywords}

Monocytes; platelets; monocyte-platelet complexes; heart failure; pharmacological intervention 


\section{Heart Failure and inflammation}

Cardiovascular disease is the number one cause of death in the world and chronic heart failure (HF) is an increasingly prevalent and costly multifactorial syndrome with high morbidity and mortality rates. HF affects approximately $1-3 \%$ of the population in developed countries and its prevalence rises to $\geq 10 \%$ in people over 65 years of age ${ }^{1,2}$. There are predictions of an increase in HF prevalence by more than $40 \%$ by the year $2030^{3}$ predominantly due to ageing populations, increased population prevalence of cardiometabolic abnormalities and improved survival post myocardial infarction.

HF is classified as either HF with preserved (HFPEF) or reduced (HFREF) ejection fraction and a cut-off of left ventricular ejection fraction (LVEF) above or below $50 \%$ is often used to differentiate these subtypes. The precise pathophysiological interactions, causes, and sequence of events leading to the development of HF have not been fully elucidated although HFREF is often associated with myocardial ischemia and infarction and is modifiable by several classes of pharmacologic and device therapy. HFPEF has a community prevalence at least as high as HFREF and is associated with older age, metabolic abnormalities and chronic hypertension leading to vascular and myocardial dysfunction ${ }^{4}$.

Several emerging pathophysiological paradigms implicate cardiometabolic risk factors, endothelial dysfunction (peripheral vascular, coronary vascular, and endocardial), inflammation, cardiomyocyte dysfunction, and myocardial fibrosis as key factors in the progression from healthy state to HF, including HFPEF ${ }^{5-9}$. Such hypotheses suggest that in early stage HF cardiac injury is driven by systemic inflammation and assisted by heightened platelet activation and oxidative stress arising from comorbid conditions such as hypertension, obesity, diabetes mellitus, iron deficiency, and chronic pulmonary and kidney disease ${ }^{5-7,9-15}$. The heightened systemic inflammatory response affects the peripheral and 
heart vasculature and promotes endothelial inflammation (such as coronary microvascular endothelial inflammation ${ }^{5}$, endocardial endothelial dysfunction ${ }^{16}$ ), and oxidative stress.. This triggers a series of events including progressive invasion of pro-inflammatory cells through dysfunctional, "leaky” endothelium into the myocardium, disrupted endothelial nitric oxide (NO) bioavailability, further endothelial imbalances, phosphorylation deficits of major cardiomyocyte proteins such as titin, and increased cardiomyocyte stiffness. The aggravating imbalances promote myocardial dysfunction by altering the composition of the myocardial extracellular matrix, resulting in collagen deposition and imbalances in matrix metalloproteinases (MMP) and their tissue inhibitors (TIMP). In advanced HF myocardial damage occurs and is amplified by the concurrent exposure to imbalanced systemic, endothelial, and paracrine inflammatory mediators such as tumor necrosis factor alpha (TNF $\alpha$ ), interleukins (IL) 1 and 6, C-reactive protein (CRP), monocyte chemotactic protein 1 (MCP1), reactive oxygen species (ROS), NO, transforming growth factor beta (TGF $\beta$ ) and MMP $5,17,18$.

Inflammation is a recognized factor in disease progression in both HFREF and HFPEF and a therapeutic target in this setting ${ }^{19}$. However, initial clinical trials utilizing broad antiinflammatory therapies such as anti-TNF $\alpha$ agents in chronic HF patients (predominantly HFREF) have shown limited success (reviewed in Mann $2005^{20}$ and Mann $2015^{21}$ ). Indeed there is some evidence from post-hoc analyses of the anti-TNF therapy trial that those patients receiving higher dose therapy or longer duration of treatment had more adverse outcomes including heart failure and cardiovascular events ${ }^{22}$. One solution proposed may be to focus again on the role of innate immunological responses in $\mathrm{HF}^{21}$. Another may be individualize therapy according to the etiology, severity and even subtype of HF (HFREF or HFPEF) due to the different nature of underlying causative and pathophysiological factors, associated comorbidities, and clinical presentation of the disease. For example, it is 
noteworthy that anti-inflammatory therapy using injections of modified autologous blood to non-specifically downregulate pro-inflammatory cytokines and increase production of antiinflammatory cytokines, showed benefits in patients with non-ischemic cardiomyopathy or patients with milder heart failure (NYHA class II) despite overall neutral results ${ }^{23}$. A further approach might borrow from several large scale clinical trials which have been initiated in the setting of atherosclerosis, testing the effect of specific inhibitors of the IL1-TNF $\alpha$-IL6 pathway and related inflammatory pathways (oxidized-low density lipoprotein, P-selectin, phospholipase A2) that act to reduce inflammation in damage-sensitive systems such as the vessel wall, the monocyte/macrophage system, the adipose tissue, and the liver (reviewed in Ridker $2014^{24}$ ). The results of these trials may advance the case for new, targeted antiinflammatory therapies for chronic cardiovascular diseases including HF. While, on one hand, a more effective therapeutic approach may benefit from targeting specific inflammatory mediators (such as monocytes) and/or specific inflammatory pathway(s) or components within this pathway(s) which have significant contribution to HF pathogenesis and progression, there has been limited success of targeted approaches to date. Undoubtedly further research is required to help define the relevant specific cellular partners and inflammatory pathways with the biggest potential impact for HF immunopathogenesis. Currently, anti-inflammatory therapy in HF patients is prescribed based on comorbidities and syndromes including atherosclerosis, acute coronary syndrome (ACS), previous MI, ischemic and non-ischemic CAD, myocardial ischemia, and atrial fibrillation. It involves, for example, the use of statins, anti-coagulants (aspirin, warfarin), corticosteroids, and non-steroidal antiinflammatory drugs (e.g. ibuprofen, naproxen) and while some studies have observed benefits associated with anti-inflammatory therapies to date, in many cases large scale studies of these therapies have resulted in neutral or even adverse effects in the failing heart ${ }^{21,25,26}$. 
Alternatively, an approach for beneficially modulating inflammation in HF may be the use of combination therapy to target platelet activation, endothelial dysfunction and/or oxidative stress alongside inflammation and inflammatory cell activation. Benefits of restoring NO signalling (using, for example, endothelial NO synthase enhancers or NO donors) which modulate the pathway at the center of endothelial dysfunction, and of restoring endothelial function and normalizing platelet function have been shown to improve cardiac function in experimental animal models of cardiac stress, injury and HF(PEF) ${ }^{27-30}$. A novel endothelial therapeutic approach with potential application in the HF setting utilized Protective Antioxidant Carriers for Endothelial Targeting (PACkET) to facilitate endothelial-targeted delivery of antioxidant enzymes (catalase and superoxide dismutase). This therapy provided vascular anti-oxidant and anti-inflammatory protection in animal models of inflammation and oxidative stress ${ }^{31}$. In addition, inhibition of platelet activation was shown to prevent cardiac inflammation, fibrosis and adverse HF remodelling in response to angiotensin II insult in mouse models ${ }^{32}$, and had beneficial effects (not confined to prevention of thromboembolic complications) on post chronic MI HF remodelling in rats with coronary ligation ${ }^{33}$.

Building on these promising non-clinical data, an approach targeting endothelial function, platelet activation, with or without anti-inflammatory therapy may improve HF treatment and prevention. Few studies have reported on this strategy in the clinic. In practice, similar to the situation with anti-inflammatory therapies in HF patients, pharmacological agents aimed at improving endothelial function and regulating platelet activity are only being used to treat patients with HF if they present with concomitant peripheral, cardiac or cerebral vascular disease, congestion, atrial fibrillation, or stroke. In this regard, retrospective observations about the beneficial impact of chronic, low dose antiplatelet therapy in HF have been made ${ }^{34}$ and disputed ${ }^{35}$. Furthermore, among patients with reduced LVEF who were in sinus rhythm, there was no significant overall difference in outcome between treatment with warfarin and 
treatment with aspirin ${ }^{36}$. Therefore, existing clinical studies on pharmacological inhibition of inflammation, leukocyte/monocyte, and platelet function and data examining the monocyteplatelet interaction and its antagonism in HF are presented and discussed in this review. Overall, in the management of inflammation in HF there may be a need not only for further evaluation of novel pharmacological agents, but also novel therapeutic strategies which are able to regulate and target inflammatory cell-cell interactions and communication in the circulation. This may be of particular value in the coronary vasculature where endothelial dysfunction, inflammatory cell interactions and inflammatory mediator release from those cells (e.g. TNF $\alpha$, IL6) may be critical to the development and progression of HF.

\section{Monocytes and platelets as mediators of cardiovascular inflammation in}

\section{Heart Failure}

Platelets and monocytes are the principal cellular mediators of hemostasis in response to cardiovascular injury (reviewed in Rondina 2013 and Fernandez-Velasco $2014^{37,38}$ ). Platelets, however, also play a major role in pathogenic thrombosis as a result of plaque rupture and endothelial dysfunction in atherothrombotic vascular diseases such as ACS, CAD, MI, cerebral ischaemia and cerebral ischaemic attack. Platelets are mediators of inflammation and atherogenesis via interactions with leukocytes (monocytes, lymphocytes, neutrophils, basophils, and eosinophils) and the endothelium. A mechanistic role for platelets in the development of acute and chronic HF has been described ${ }^{39,40}$. HF patients were shown to have higher mean platelet volume, increased whole blood aggregation, and higher levels of adhesion proteins including soluble and platelet-bound P-selectin and soluble CD40 ligand (sCD40L) ${ }^{41-47}$. Yet, despite the robust platelet activation and increase in activation markers, three studies in HF patients have shown that these may not modulate HF directly, but rather

relate to future cardiovascular events via associated comorbidities ${ }^{47-49}$. In the first study, 
Chung et al. reported increased levels of markers of platelet activation (soluble P-selectin, platelet surface P-selectin, and CD63) in stable congestive HFREF patients ( compared to healthy controls but not compared to CAD patients with normal LVEF $>50 \%{ }^{47}$. However, since none of the platelet markers in HF and CAD patients were predictive of future events, platelet abnormalities in HF were claimed to relate to associated comorbidities. A second study in ambulatory HFREF patients also showed heightened platelet activity unaffected by aspirin therapy compared to healthy controls ${ }^{48}$. The degree of platelet activation was similar in ischemic and non-ischemic HF patients and was not related to disease severity or to outcome. Similarly, results from the congestive HF EPCOT trial which sought to assess the diagnostic utility of the platelet function analyzer (PFA-100) in HF, showed no significant differences when patients were divided by incidence of vascular events, emergency revascularization needs, survival, or HF etiology, suggesting that platelet abnormalities do not reliably predict clinical outcomes in this population ${ }^{49}$. Furthermore, in three trials of aspirin versus warfarin in patients without concomitant anticoagulant or antiplatelet therapy and without a definite indication for antiplatelet therapy, there have been inconsistent results. The WASH and WATCH trials identified an increased risk of cardiovascular and HF events in aspirin users compared with warfarin users ${ }^{50,51}$, whereas the WARCEF trial did not demonstrate a benefit of aspirin compared with warfarin use in this population ${ }^{36}$.

From a mechanistic viewpoint, a major role is anticipated for activated platelets in boosting systemic inflammatory responses, enhancing endothelial permeability and malfunction, and influencing subsequent tissue damage in cardiovascular disease and HF. These processes are regulated by platelet-induced activation of blood leukocytes and endothelial cells, enhanced platelet and leukocyte adhesion to endothelial cells, and enhanced leukocyte invasion into affected tissues. 
Leukocytes, particularly monocytes, play important roles in various cardiovascular (patho)physiological conditions including cardiovascular inflammation, wound healing, atherosclerosis, MI, ischemia, hypertension, and HF (reviewed in Swirski 2013 and Ghattas $2014^{52,53}$ ). The inflammatory phase of acute and chronic cardiac damage is characterized by inflamed myocardial tissue and endothelium of the adjacent coronary microvasculature. This results in chemo-attraction of monocytes, both of myeloid bone marrow ${ }^{54}$ or splenic ${ }^{55,56}$ origin, via chemotactic signals (such as MCP1) secreted from susceptible endothelium and subsequent infiltration of these cells into the tissue. In the tissue, monocytes differentiate into macrophages with distinct phenotypic and functional properties dependent upon local cytokine stimuli. These macrophages release cytokines and mediators such as TNF $\alpha, \mathrm{MCP} 1$, IL8, IL1, MMPs, and TGF $\beta$ which collectively contribute to the local inflammatory and fibrotic responses. Monocytes and macrophages are known to be major drivers of the inflammatory and fibrotic processes in cardiac disease and $\mathrm{HF}^{57,58}$. Increased activation of monocytes and abundant monocyte/macrophage infiltrates are seen in pressure-overloaded hearts in early and late stage HF and associate with exaggerated inflammation, tissue injury, fibrosis, but also tissue repair and revascularization ${ }^{59-61}$ signifying a complex dual role of monocytes/macrophages in $\mathrm{HF}^{57}$.

\section{Mechanisms of platelet and monocyte activation and interactions with the endothelium}

\section{Platelet and endothelial activation}

As described above, the main function of platelets is hemostasis by formation of blood clots from activation of coagulation cascades as well as preservation of the endothelial balance and contribution to inflammation. Under physiological conditions NO derived from the L- 
arginine pathway and cyclooxygenase (COX)-2-derived prostacyclin ( $\left.\mathrm{PGI}_{2}\right)$ are secreted from intact endothelium to oppose platelet activation and adhesion ${ }^{62}$. In malfunctioning, inflamed or disrupted endothelium, the release of inflammatory and stimulatory factors (adenosine diphosphate (ADP), Von Willebrand factor (VWF), tissue factor (TF), MCP1), the upregulation of adhesion molecules (E- and P-selectin, integrins (intercellular and vascular cell adhesion molecules (ICAM1 and VCAM1)), and the exposure and release of extracellular matrix proteins (collagen, fibrinogen, fibronectin) promote platelet shape change. This results in increased expression of pro-inflammatory and adhesion molecules (Pselectin, sCD40L, platelet integrins: glycoprotein (GP) 1b, GP1b/V/IX. GPIIb/IIIa, GPVI), stimulating platelet activation, adherence and aggregation (reviewed in Jennings 2009, Davi 2007, and van Gils $2009^{63-65}$ ). Other signals promoting platelet activation include bacterial and viral infection, leukocyte activation, hematologic diseases affecting erythrocytes (e.g. anemia), immune and autoimmune disorders. In HF, circumstances that have the potential to promote platelet activation include hemodynamic changes and vascular factors, vascular endothelial dysfunction and reduced NO formation, renin-angiotensin system activation, increased catecholamine and cytokine release. These biochemical hallmarks are associated with co-morbidities including hypertension, iron deficiency, diabetes, ischemia, peripheral vascular disease, and valvular disorders ${ }^{5,39,40}$.

Activated platelets roll along the endothelium and attach to the site of injury via the platelet integrin receptors GP1b/V/IX, GPVI, and GP1b which recognize exposed VWF, collagen, and P-selectin on endothelial cells (reviewed in Varga-Szabo $2008{ }^{66}$ ). Firm adhesion to the endothelium is mediated via the subsequent formation of additional contacts between platelets, endothelial cells and secreted extracellular matrix proteins such as GPIIbIIIa fibrinogen and GPVI / GP1a - collagen ${ }^{66}$. Following initial adhesion, platelets respond to mediators that sustain and amplify the initial activation. The main amplifiers of platelet 
activation are the soluble agonists ADP, thromboxane A2 (TXA2), and thrombin. The actions of ADP and TXA2 are the targets of the most commonly prescribed antiplatelet drugs. Both ADP and TXA2 are released from adherent platelets to promote the activation, recruitment and accumulation of additional platelets. In physiological hemostasis and, mainly, in acute pathology this may lead to the formation of a growing thrombus. ADP interacts with the platelet receptor $\mathrm{P}_{2} \mathrm{Y}_{12}$ promoting platelet activation, an interaction antagonized by the $\mathrm{P}_{2} \mathrm{Y}_{12}$ blockers clopidogrel, prasugrel, ticlopidine, ticagrelor, and cangrelor used for prevention of major vascular events in at-risk ACS and MI patients ${ }^{67,68}$. TXA2 is a transient metabolite of arachidonic acid produced by successive actions of prostaglandin- endoperoxide synthase-1 (PTGS-1 or COX1) and thromboxane synthase ${ }^{69}$. TXA2 exerts its effects by binding to its receptor expressed in various cells (platelets, endothelial cells, monocytes, macrophages, smooth muscle cells) and tissues (heart, kidney, spleen) ${ }^{70}$. TXA2 is a key early stage platelet activating signal and its suppression provides the standard explanation for the cardioprotective effects of low dose aspirin post-MI. Drugs that target the TXA2 pathways and their mechanisms of action have been reviewed by Fontana et al. ${ }^{71}$. These include not just the COX1 inhibitors (aspirin, triflusal) but also TXA2 synthase inhibitors (ozagrel, picotamide, ridogrel, EV-077) and TXA2 receptor antagonists (seratrodast, ramatroban, terutroban, picotamide, ridogrel, EV-077). Those have shown varying degrees of clinical efficacy in the treatment of peripheral artery disease, atherosclerosis, ACS, and asthma ${ }^{72-76}$. Thrombin, known for cleaving fibrinogen to fibrin, is also a potent platelet activator that is rapidly produced at sites of vascular injury ${ }^{77}$. It binds G-protein-coupled protease-activated receptors (PARs), mainly PAR1, on human platelets. Binding of thrombin to PAR1 leads to receptor cleavage and exposure of an active ligand. Anti-thrombin agents (bivalirudin, fondaparinaux, rivaroxaban, apixaban) and PAR1 inhibitors (vorapaxar, atopaxar) have been evaluated and have shown mixed effectiveness in clinical studies in patients with ACS, stable 
atherosclerotic disease, MI, stroke, and ischemia ${ }^{68,78-85}$. As described above, in HF, antiplatelet therapy is still indicated almost exclusively based on the presence of concomitant vascular disease. The use of anti-thrombotic therapy is also indicated in the setting of atrial fibrillation and data beyond this in HF are limited. Further discussion of clinical studies to date is provided below in the final section of this review ("Future perspectives on evaluation of drug therapy directed at monocyte-platelet interactions in HF”).

\section{Monocyte activation}

Monocytes and macrophages are essential components of the innate immune system with key functions in host defense to pathogens , inflammation, immune regulation, tissue remodelling, homeostasis, and metabolism (phagocytosis/removal of cell debris, iron recycling for reuse by the host, wound healing). Upon sensing of an activating signal, monocytes migrate through the endothelium into respective tissues and differentiate into macrophage effector cells and replenish long-lived resident tissue macrophages in the liver (Kupffer cells), spleen, peritoneum, central nervous system (microglial cells), bone (osteoclasts), and connective tissue (histiocytes) ${ }^{86}$. There are different types of activating signals including infection components (bacterial LPS, lipopeptide, flagelin, and deoxyribonucleic acid (DNA); viral envelope glycoproteins; fungal zymosan and $\beta$-glycan), endogenous danger signals (cytokines: TNF $\alpha$, IL1 $\beta$, MCP1; soluble mediators: CD40 ligand, TXA2, platelet activating factors (PAF), leukotrienes, low-density lipoprotein, glucose), necrotic cells, and pathophysiological events (hypoxia, ischemia/reperfusion). These signals act on specific signal receptors on monocytes/macrophages which may or may not trigger an associated immune response. Homeostatic clearance of cells generated during tissue remodelling, clearance of apoptotic cells, and iron recycling from senescent erythrocytes is mediated by scavenger receptors, integrins, complement receptors, phosphatidyl serine 
receptors, and thrombospondin receptor (reviewed in Kono $20088^{87}$ ). These regulatory processes do not generate an immune response or mediator release. Meanwhile, clearance of necrotic material containing endogenous activators like histones, DNA, heat-shock and nuclear proteins generated as a result of trauma and stress, as well as stress signals from chronic and acute inflammation and remodelling (ischemia/hypoxia, hypertension, cardiac stiffness/fibrosis, high cardiac filling pressures) are regulated by Toll-like receptors (TLR), the IL1 receptor, intracellular pattern recognition receptors, and chemokine receptors. In addition, bacteria and virus sensing activates pattern recognition receptors like TLR, cytoplasmic Nod-like receptors and retinoic acid inducible gene I-like helicase receptors, scavenger receptors (like CD163), the LPS receptor CD14, and C-lectins. This promotes pathogen elimination or neutralization by phagocytosis, antigen presentation, and cytokine release ${ }^{87}$. These interactions induce an immune response with increased monocyte activation and monocytosis, which are characteristic for (auto)-immune and inflammatory diseases as well as for chronic inflammation associated with cardiovascular diseases ${ }^{88,89}$. Ultimately, monocyte activation is reflected by a sequence of events including: 1) increased expression of monocyte surface proteins (MCP1 receptor CCR2, fractalkine receptor CX3CR1, P-selectin glycoprotein 1 (PSGL1), L-selectin, integrins, and CD40); 2) activation of intracellular inflammatory signalling cascades (nuclear factor kappa B (NFkB), intracellular response factors, signal transducer and activator of transcription); 3) release of pro-inflammatory cytokines (MCP1, TNF $\alpha$, IL1 $\beta$, IL8, IL6, TF) and ROS; 4) expression of remodelling and angiogenesis-associated mediators (MMP, TIMP, vascular endothelial growth factor); and 5) a change in monocyte shape and actin cytoskeleton rearrangements (Rho, Rac and Cdc42 GTPases). Overall this results in monocyte mobilization and migration into tissue via increased MMP expression, upregulation of endothelial adhesion molecules (selectins, ICAM1, VCAM1), and NO synthesis. 


\section{Mutual Platelet-Monocyte-Endothelial Cell activation}

A striking feature of monocyte/macrophage activation during cardiovascular stress or injury is the complex, dynamic communication network between circulating monocytes and activated platelets; circulating monocytes and activated endothelial cells; and platelets and endothelial cells, outlined in a recent review by van Gils et al. ${ }^{65}$. The precise sequence of the events remains unclear and may indeed be heterogeneous, but the importance of this mutual platelet-monocyte-endothelial cell activation is established in cardiovascular pathophysiology 90-93.

Figure 1 presents the main events taking place within the platelet - monocyte - endothelial cell network. Under pathophysiological conditions, activated platelets adhere to the endothelium, secrete chemokines (MCP1, IL1 $\beta$, chemokine C-C motif ligand 5 (CCL5), TXA2, TF, PAF, macrophage inflammatory protein), and increase expression of adhesion molecules (P-selectin, GP receptors, CD40L) to promote the recruitment of circulating monocytes. The latter roll, adhere (mainly via P-selectin/PSGL1, GP/integrin, and CD40L/CD40 interactions), and eventually migrate through the endothelium into adjacent tissues, facilitated by MMPs. In other circumstances, platelets may be activated while in the circulation, for example by cytokines released in systemic inflammation or thromboembolism (acute MI), by soluble agents released from platelets present at unstable thrombi ${ }^{94}$, or as a result of turbulent flow. These activated platelets bind preferentially to circulating monocytes in a P-selectin/PSGL1-mediated fashion and form monocyte-platelet complexes (MPCs) which show increased adhesive and migratory properties and aid the recruitment and activation of other, non-complexed monocytes ${ }^{95}$. Some of the mechanisms involved include NFkB pathway activation, L-selectin shedding, increased integrin expression and activity, 
increased secretion of pro-inflammatory mediators and TF expression ${ }^{96,97}$. MPCs are therefore regarded as functionally important inflammatory mediators.

Briefly, in addition to the interactions between monocytes and platelets, platelet adhesion to the endothelium causes both platelet activation and endothelial activation. The interaction mediates the release of inflammatory chemokines (CCL5, platelet factor 4 (PF4), IL1 $\beta$, macrophage migration inhibitory factor (MIF)) and mediators (TF, thrombin, PAF, ADP, TXA2), and upregulation of adhesion molecules (CD40L, P-selectin) from adherent platelets. In endothelial cells it activates NFאB and ROS production, upregulates endothelial adhesion molecules (VCAM1, ICAM1, E- and P-selectin), and regulates the secretion of different cytokines and mediators (MCP1, VWF, IL6, IL8, MMPs, granulocyte-macrophage colony stimulating factor) aimed at further monocyte and platelet activation, monocyte transmigration and macrophage differentiation ${ }^{64,98}$.

Another important aspect of monocyte/macrophage activation is the polarization of circulating monocytes to tissue macrophages of either the classical/M1 or the alternative/M2 subset. This process is dependent on the type of monocyte activating signal and determines the phenotypic and functional traits of these cells and therefore the outcome of an immuneinflammatory response. Classical/M1 macrophages are induced by pro-inflammatory mediators like interferon gamma (IFN $\gamma$ ), TNF $\alpha$, and pathogen-associated TLR ligands (LPS). They express high levels of pro-inflammatory cytokines (IL1, TNF $\alpha$, IFN $\gamma$, IL6, IL8, IL12, IL23), produce high levels of reactive nitrogen and oxygen intermediates, stimulate T-helper type 1 responses, have strong anti-microbial and anti-tumor activity, are involved in intracellular parasite killing, and mediate tissue destruction ${ }^{99,100}$. M1 macrophage polarization regulates and is regulated by acute inflammation and infection, such as viral and bacterial infection, arthritis, atherosclerosis, diabetes (insulin resistance), and glomerulonephritis. Alternative/M2 macrophage activation is more complex due to the 
existence of several M2 subtypes. M2 macrophages can be induced by IL4, IL13; immune complexes, glucocorticoids, TLR and IL1 receptor ligands; or IL10, TGF $\beta$, IL1 $\beta$, and IL6 and are involved in parasite containment, T-helper type 2 responses, and tumor promotion. They are highly phagocytic, and express high levels of scavenger, mannose and galactose receptors ${ }^{99,100}$. M2 polarization is mostly associated with chronic infection and inflammation, such as granuloma, helminths, cancers, renal and liver fibrosis, asthma, dermatitis, and wound healing (reviewed in Sica $2012{ }^{100}$ ). M2 are also involved in matrix deposition, tissue remodelling, angiogenesis, immune regulation, and immune suppression which is of importance in chronic fibro-inflammation observed in chronic HF.

\section{The importance of monocyte-platelet interactions and complexes in Heart}

\section{Failure}

As described above, platelets and monocytes have been separately implicated in HF pathogenesis and pathophysiology $37,39,40,58$.

It is possible that a crucial, but insufficiently explored pathophysiological aspect of HF is the interaction between the endothelium, platelets, and monocytes in the setting of chronic, low grade inflammation arising from myocardial damage. A dysregulated, augmented cross talk between monocytes and platelets may be a critical factor influencing both the development and the progression of HF.

The ability of activated platelets to interact with leukocytes, particularly monocytes, and form complexes in the peripheral circulation has been described long ago ${ }^{101}$. MPC formation is increased in patients with autoimmune diseases such as rheumatoid arthritis, systemic lupus erythematosus, and antiphospholipid syndrome ${ }^{102}$. MPCs are also increased and can be detected in the peripheral blood of patients with acute thrombotic disorders including acute 
MI ${ }^{91,103,104}$, stroke ${ }^{105-107}$, ACS ${ }^{90,108}$, stable CAD ${ }^{109}$, atherosclerosis ${ }^{110,111}$, as well as in patients with atherothrombotic risk factors such as hypertension ${ }^{112}$ and type I diabetes ${ }^{113}$. The significance of MPCs in cardiovascular disease is further supported by the increased levels of MPCs found in the blood of patients following cardiovascular intervention (cardiopulmonary bypass) and by the positive correlation of MPCs with cardiovascular disease severity and prognosis ${ }^{92,114,115}$.

Since these conditions are both risk and etiological factors for HF, the importance of MPCs in HF development has also been recognized ${ }^{46,116}$. Research in this area, however, is scarce and is challenged by the diverging etiologies and pathophysiology of the two types of HF, HFREF and HFPEF. While most research, including monocyte and platelet research, has traditionally been orientated to resolving interactions and disease mechanisms in the setting of ischemic heart disease and HFREF, accumulating new knowledge in HFPEF has highlighted the contribution of circulating factors, including leukocytes and platelets, to disease development and progression ${ }^{5}$. Indeed evidence of monocyte and platelet activation separately has been shown in pre-HF and minimally-symptomatic phases of HFPEF ${ }^{117}$. However, to date, mutual monocyte-platelet interaction/activation has not been investigated in HFPEF.

While myocardial damage in HFREF was shown to be driven by oxidative stress to the myocardium originating from within the cardiomyocyte, in HFPEF the myriad of existing comorbidities and systemic and vascular inflammation (i.e. leukocyte and endothelial inflammation, platelet activation) are known to orchestrate cardiac remodeling and dysfunction ${ }^{5,6}$. In this regard, the contribution of monocyte-platelet interactions and MPCs may also be important in the pathophysiology of HFPEF.

Despite this, the few existing studies that have looked at MPCs in HF have examined only patients with HFREF. Increased MPC formation has recently been reported in ischemic HF in 
patients with acute as well as chronic stable HFREF $(\mathrm{LVEF}<40 \%){ }^{92}$. This was associated with increased MPC formation preferentially with pro-inflammatory monocyte subsets $\left(\mathrm{CD} 14^{++} \mathrm{CD}^{-}{ }^{-}\right.$and $\left.\mathrm{CD} 14^{++} \mathrm{CD} 16^{+}\right)$in these HFREF patients compared with patients with stable CAD but no $\mathrm{HF}^{92}$. Generally, the extent of MPC formation reflects the level of platelet activation and hyperactivity and is an index of blood thrombogenicity ${ }^{103}$. More recently, platelet-monocyte interactions have emerged as an important pathophysiological link between thrombosis and inflammation, mainly due to platelet-induced inflammatory cytokine and prostanoid production from monocytes as well as increased monocyte endothelial adhesiveness ${ }^{64,95-97,118,119}$. Those features highlight a likely regulatory role of monocyteplatelet interactions and MPCs not only in acute cardiac ischemia, vascular disease and thrombosis but also in chronic non-ischemic $\mathrm{HF}^{93}$. Indeed, abnormal platelet activity in chronic stable non-ischemic HFREF has been reported in one study, but these abnormalities were not predictive of outcome, notwithstanding the relatively small sample size ${ }^{47}$. Furthermore, the authors concluded that platelet activation may simply be related to the comorbidities. Whether related to comorbidities or HF, it remains plausible that MPC formation contributes to the progression of fibro-inflammation and worsening of outcomes in HF, not only in HFREF, but also in HFPEF, which requires further evaluation. Areas for future research include the circulation time, clearance, and exact role of these complexes in vivo, in the setting of HF. Mechanistically, even though much is known about the triggers of MPC formation in the blood, the lack of data on MPCs in vivo hinders progress in defining the significance of MPCs in HF pathophysiology. The magnitude of MPC formation is primarily dependent on platelet activation and to some extent also on monocyte activation ${ }^{95,120}$. The main protein interaction controlling platelet-monocyte binding at the vascular wall and in the circulation (MPC formation) is the one between P-selectin on activated platelets and PSGL1 on monocytes ${ }^{95,121}$ (Figure 1). The crucial role of this 
interaction for MPC formation was verified by the use of P-selectin blocking antibodies which abrogated platelet adhesion to monocytes, whereas blocking other ligands had only minor effects ${ }^{95,122}$. As described above, binding of monocytes to activated platelets to form MPCs induces expression of activating, pro-inflammatory cytokines and mediators from monocytes including IL1 $\beta$, IL8, MCP1, and intracellular NFאB inflammatory signalling (Figure 1); and anti-P-selectin antibodies reduced cytokine production ${ }^{118}$. In addition, an increase in high-sensitivity CRP, enhancement of pro-inflammatory monocytes subsets $\left(\mathrm{CD} 14^{++} \mathrm{CD} 16^{+}\right)$, and increased monocyte adhesion to endothelial cells was reported as a result of increased platelet activation and MPC formation ${ }^{119}$. Those effects were reduced by the COX2 selective inhibitor NS-398, aspirin, and the -selective antagonist of prostaglandin E receptors 1 and 2, AH6809 ${ }^{119}$. Monocytes within MPCs show increased stable adhesiveness to activated endothelium due to increased expression and activity of $\beta 1$ and $\beta 2$ integrins and decreased expression of L-selectin which is involved in early monocyte rolling along the endothelium ${ }^{96}$. These result in increased monocyte adhesion to ICAM1, VCAM1, and fibronectin and facilitate monocyte transendothelial migration.

The circulation time and clearance of MPCs are not well defined and differ between humans and animals. In apolipoprotein-E-deficient mice, MPC formation was caused by injection of activated platelets. This was accompanied by increased CCL5, PF4, and increased VCAM1mediated monocyte binding to atherosclerotic endothelium. MPCs were found to be relatively short-lived (3-4 h) and cleared upon monocyte transmigration ${ }^{121}$. Similarly, in primates MPC lifespan upon injection of thrombin-activated platelets was approximately 30 min while in patients with percutaneous coronary intervention, MPCs were detectable for up to $24 \mathrm{~h}^{103}$. Similarly, acute MI patients registered higher levels of MPC formation with no increase in circulating P-selectin-expressing platelets. Of note, the lifespan of MPCs did not relate to Pselectin shedding from platelet surface, which occurs several hours after MPC formation but 
may be related to increased adhesive capacity of these complexes ${ }^{103}$. A paper by van Gils et

al. ${ }^{123}$ has shed some light on the regulation of MPCs during transendothelial migration. The authors demonstrated in vivo that platelets localize to PSGL1 regions at the uropod of monocytes upon migration and detach from migrating monocytes and remain at the endothelial surface. MPC dissociation was associated with monocyte PSGL1 redistribution and mechanical stress, but not with reduced PSGL1 expression, reduced platelet-binding capacity of monocytes, or the type of endothelial matrix protein.

Finally, the circulation time and clearance of MPCs might also depend on the extent of platelet phagocytosis mediated by activated monocytes, but this issue requires further study in the setting of HF.

\section{Future perspectives on evaluation of drug therapy directed at monocyte- platelet interactions in $\mathrm{HF}$}

Taken together, the available evidence shows heart failure is a hypercoagulable state independently of the presence of sinus rhythm and might support the hypothesis that monocyte-platelet-endothelial interactions and MPCs have an important role in HFREF as well as HFPEF pathogenesis and progression. Accepting this hypothesis would further point to putative clinical benefit of therapies directed at low-grade, chronic inflammation as well as platelet activation in the setting of HF. However, there are few conclusive clinical studies to support this hypothesis and, indeed, data from several large clinical trials have shown conflicting and even adverse outcomes with anti-thrombotic and anti-inflammatory therapy in HF (Table 1).

In reconciling these observations several factors must be considered. Firstly, many of the studies to date have not been appropriately powered, prospective, randomized studies 
designed to address the hypothesis. Of the prospective, randomized studies, the HELAS ${ }^{124}$ and WASH ${ }^{50}$ studies of anti-platelet/anti-coagulant strategies in HF were underpowered, as were anti-inflammatory studies of thalidomide, IV-IG therapy and IL-1 receptor antagonist anakinra in HF populations ${ }^{125-127}$. In the larger WATCH study ${ }^{51}$, which was terminated prematurely arising from recruitment difficulties, achieving 1587 of a planned 4500 participants, there were no differences in the primary endpoint of death, non-fatal MI and non-fatal stroke between aspirin, warfarin and clopidogrel. However, this study raised a concern about excess hospitalizations for HF associated with aspirin versus warfarin and was in direct contrast to the subsequent WARCEF study ${ }^{36}$, which was adequately powered, also showed no difference in primary endpoint between aspirin and warfarin, yet showed a trend to increased hospitalizations for HF in the warfarin versus aspirin treated patients.

Secondly, almost all of the reported HF studies were carried out in HFREF patients, frequently with advanced disease, whereas there is some evidence from post-hoc analyses of the ACCLAIM study that anti-inflammatory therapies are likely to be most effective and beneficial in early stage $\mathrm{HF}^{23}$. Furthermore, the possible benefit of anti-thrombotic therapy in HFPEF has yet to be formally tested in prospective, controlled studies. A small number of retrospective or observational studies have suggested that platelet activation is a feature of HFPEF and may be modifiable (Table 1$)^{34,127,128}$. There is only one small study of antiinflammatory therapy with IL-1 receptor antagonist anakinra in HFPEF ${ }^{127}$ and one small prospective study of the same anti-inflammatory therapy in HFPEF currently recruiting (clinicaltrials.gov identifier NCT02173548).

Thirdly, inappropriate dosing which can cause off-target or adverse effects and risks for the patient that eventually outweigh any clinical benefits may be an important reason for failure of anti-thrombotic/anti-inflammatory therapy in HF to date. For example, aspirin has proven anti-platelet effects at low doses ( $<80 \mathrm{mg}$ ) commonly used in Europe and dose-related 
adverse effects at higher doses. Of particular concern in HF, modulation of vasodilating prostaglandins can occur at higher aspirin doses and it has been shown that there are dosedependent adverse renal effects of aspirin at doses $>80 \mathrm{mg}$ daily ${ }^{129}$. Despite this, in all of the prospective, randomized studies of aspirin in HF to date, higher daily doses were used.

Similarly, it was shown in the ATTACH study that there is a significant increase in death and HF hospitalization with higher dose and longer treatment of the TNF $\alpha$ antagonist infliximab ${ }^{22}$. Given the chronic, low grade nature of inflammation in HF, doses and duration of antiinflammatory therapy should be considered in the study design.

A forth consideration is that many of the trials include patients who may fall into the category of “indication for anti-thrombotic or anti-inflammatory therapy” independently of HF (including patients with ischemic heart disease, peripheral vascular disease, MI, atherosclerosis, stroke, atrial fibrillation), which makes evaluation of the benefits of antithrombotic/anti-inflammatory drugs for HF very difficult. A related concern is the highly prevalent use of medications such as statins and aspirin among at-risk populations that persists long after the development of HF. However, as HF is a syndrome arising from other cardiovascular abnormalities, and involves multi-system pathology, the distinction between comorbidity and etiological factors is blurred and it may be unrealistic or even unwise to exclude patients with other conditions responsive to anti-thrombotic/anti-inflammatory therapy.

Finally, more work is needed to expand our understanding of platelet-targeting agents beyond simple anti-coagulation/thrombotic agents, but also as means for regulation / modulation of other platelet functions, as well as leukocyte (monocyte) and endothelial function. The emerging importance of the platelet and endothelium in modulating tumor cell intravasation and extravasation ${ }^{130}$ may have parallels with monocyte/macrophage intravasation in the myocardium as a key step in the pathogenesis of myocardial dysfunction 
in HF. Furthermore, it may be rational to use agents that interfere not with a single type of cell or event but with intercellular communication and actions. Therefore, there may be a role for modulating myocardial fibrosis using pharmacological agents that target monocyte as well as platelet function, the interaction of these cells in the circulation, MPC formation and the intravasation of monocyte-derived macrophages via inflamed vascular endothelium into the failing heart.

This concept has been applied to atherosclerosis, where binding of platelet P-selectin to monocyte PSGL1 has been shown to promote activation of the interacting cells, release of pro-inflammatory mediators, endothelial adhesiveness and activation, monocyte transmigration into adjacent tissues, and thrombogenicity while its blockage had beneficial cardiovascular effects in the setting of atherosclerosis ${ }^{110,120-123}$. While it is long recognized that the severity of interstitial fibrosis closely correlates with the extent of LV hypertrophy and impairment of ejection fraction ${ }^{131,132}$, there is now a recognition of the potential importance of perivascular fibrosis in non-ischemic HF ${ }^{133}$. In addition, suppressed NO production and responsiveness, increased P-selectin and circulating MPCs in hypertension, the main etiological factor associated with $\mathrm{HFPEF}^{112}$, and increased serum soluble P-selectin in patients with diastolic dysfunction (independent of diabetes or CAD) ${ }^{134}$ indicate a possible important contribution of the P-selectin - PSGL1 pathway in driving chronic HF, particularly HFPEF. Soluble, platelet-bound, and total P-selectin are also significantly increased in congestive HFREF (LVEF $<50 \%){ }^{47}$. While the prognostic significance of this has yet to be determined it is interesting to note that a recent 10-year long-term follow-up study showed that soluble P-selectin has prognostic value in predicting cardiac events including cardiac death, non-fatal MI, and ACS with hospitalization in patients with preserved LVEF $>50 \%$ ${ }^{135}$. However, no study to date has evaluated the relationship between P-selectin levels and outcome in HF, nor explored the potential benefits of direct P-selectin - PSGL1 inhibition in 
therapy of chronic HF in patients. Interesting evidence from a transgenic mouse model of chronic HF with cardiac-specific overexpression of TNF $\alpha$ clearly showed that targeted disruption of P-selectin gene alongside ICAM-1 expressed by immune-inflammatory and endothelial cells improves cardiac function and survival ${ }^{136}$. This may point to the benefit of modifying both platelet and monocyte activation in patients as outlined by Moertl et al. who showed that treatment with high dose (4 g/day) omega-3 polyunsaturated fatty acids reduced P-selectin, TF, and inflammatory cytokine release (IL6, TNF $\alpha$ ) in patients with advanced non-ischemic, chronic HFREF ${ }^{137}$. From a non-pharmacological perspective, exercise training (20 weeks) also significantly decreased soluble P-selectin and CD40 levels reflecting monocyte and platelet activation in patients with mild to moderate chronic $\mathrm{HF}^{138}$.

Other pharmacological agents aimed at inhibiting platelet or monocyte function, or both, with a potential to regulate monocyte-platelet interaction and MPC formation include antithrombin agents, nitrates, PAR1 inhibitors, ADP antagonists, and TXA2 antagonists. The clinical benefits of these drugs in the context of wider, largely acute cardiovascular disease including peripheral artery disease, atherosclerosis, ACS, MI, and ischemia have been extensively. However, in the setting of HF, the evidence is scant. For example, a combination of aspirin (325 mg/day) and ADP P2Y 12 blocker clopidogrel (75 mg/d) in advanced congestive HFREF (PLUTO-CHF trial) (LVEF $<40 \%$, NYHA $\geq 2$ ) resulted in significant inhibition of platelet activation (collagen-induced aggregation in plasma and whole blood) and expression of adhesion molecules (PECAM1, GPIb, GP IIb/IIIa antigen, GP IIb/IIIa, CD151) including P-selectin when compared with patients taking only aspirin ${ }^{139}$. The combined therapy also reduced formation of platelet-leukocyte microparticles, an index of increased MPC formation ${ }^{139}$. These effects were sustained in the broad spectrum of patients with HF independent of its etiology, severity (NYHA), or myocardial contractility ${ }^{140}$. Similar effects on platelet function and platelet-leukocyte microparticles were also achieved by a 
combination of aspirin (325 mg/d) and selective serotonin reuptake inhibitors in congestive HFREF (LVEF $<40 \%$, NYHA $\geq 2$ ) ${ }^{141}$. Similarly, treatment of stable, severe HFREF patients (NYHA III/IV) with the oral direct Factor Xa inhibitor rivaroxaban in a small study successfully reduced platelet activation and hypercoagulability, thus minimizing risk and improving clinical prognosis ${ }^{142}$. Finally, in a study of 25 chronic HFREF patients awaiting transplantation, 11 received oral anti-thrombotic agents (target INR 2-3) associated with reduced fibrinolysis, inflammation, and endothelial dysfunction ${ }^{143}$. These data once again suggest that important links exist between platelet, monocyte and endothelial cell function in HF and that it may be possible to modulate not only platelet function, but platelet-monocyte interactions using available pharmacological therapy. Furthermore, from the perspective of HF management, not only is evidence scant, but also almost exclusively in HFREF, rather than HFPEF patients. Although retrospective, observational data provide evidence of an association between antiplatelet therapy using COX1 inhibition with low dose aspirin (75 $\mathrm{mg} / \mathrm{d}$ ) and improved HF outcomes in an unselected, mixed HFREF and HFPEF population (average LVEF: $40 \pm 15 \%$ ) ${ }^{34}$ more prospective, randomized data are needed to explore the mechanisms and optimal pharmacological and non-pharmacological management of the adverse consequences of platelet-monocyte interactions in HF, particularly with preserved ejection fraction.

\section{Conclusion}

There are several emerging paradigms in the understanding of the pathophysiology of HF which implicate cardio-metabolic risk factors, inflammation, endothelial dysfunction, myocardial fibrosis, and myocyte dysfunction. The monocyte - platelet interaction has emerged in limited studies to date as a potentially important pathophysiological link between inflammation, thrombosis, endothelial activation, and myocardial dysfunction. This 
interaction may play a crucial role in promoting cardiac dysfunction by modulating thrombogenicity, inflammation, endothelial dysfunction, and oxidative stress and facilitating monocyte to macrophage infiltration in the myocardium promoting fibrosis and dysfunction. This may also be of particular importance in HFPEF, which has been under-investigated to date and is now acknowledged as a syndrome with a strong inflammatory component in preand minimally symptomatic phases, promoting a reactive cardiac fibrosis and dysfunction ${ }^{5-}$ ${ }^{7,9}$. It is entirely plausible to draw the conclusion that inflammation is a correlate and not causative in HF from the clinical work to date in HFREF ${ }^{21}$ and that therapies targeting the platelet are of little value in HF without established underlying indications. However, there may be lessons to learn in the design of future studies from the evidence base to date. Furthermore, the expanding knowledge in our understanding of immune modulation as well as molecular profiling to identify target patient subsets in a more personalized strategy offer hope. Finally, more studies in chronic HF, particularly HFPEF, are needed to properly assess the value of including therapeutic agents which target not only platelets and platelet activation, as current therapies do, but also monocytes ${ }^{117}$, and more specifically plateletmonocyte interactions. 


\section{References}

1. Seferovic PM, Stoerk S, Filippatos G, et al. Organization of heart failure management in European Society of Cardiology member countries: survey of the Heart Failure Association of the European Society of Cardiology in collaboration with the Heart Failure National Societies/Working Groups. Eur J Heart Fail. Sep 2013;15(9):947959.

2. Go AS, Mozaffarian D, Roger VL, et al. Heart Disease and Stroke Statistics--2014 Update: A Report From the American Heart Association. Circulation. Dec 182013.

3. Heidenreich PA, Albert NM, Allen LA, et al. Forecasting the impact of heart failure in the United States: a policy statement from the American Heart Association. Circulation. Heart failure. May 2013;6(3):606-619.

4. James S, Barton D, O'Connell E, et al. Life expectancy for community-based patients with heart failure from time of diagnosis. Int J Cardiol. Jan 15 2015;178:268-274.

5. Paulus WJ, Tschope C. A novel paradigm for heart failure with preserved ejection fraction: comorbidities drive myocardial dysfunction and remodeling through coronary microvascular endothelial inflammation. J Am Coll Cardiol. Jul 23 2013;62(4):263-271.

6. Tschope C, Van Linthout S. New insights in (inter)cellular mechanisms by heart failure with preserved ejection fraction. Current heart failure reports. Dec 2014;11(4):436-444.

7. Glezeva N, Baugh JA. Role of inflammation in the pathogenesis of heart failure with preserved ejection fraction and its potential as a therapeutic target. Heart Fail Rev. Sep 2014;19(5):681-694. 
8. Andries LJ, Kaluza G, De Keulenaer GW, Mebazaa A, Brutsaert DL, Sys SU. Endocardial endothelial dysfunction and heart failure. J Card Fail. Dec 1996;2(4 Suppl):S195-202.

9. Westermann D, Lindner D, Kasner M, et al. Cardiac inflammation contributes to changes in the extracellular matrix in patients with heart failure and normal ejection fraction. Circulation. Heart failure. Jan 2011;4(1):44-52.

10. Volpe M, Camm J, Coca A, Unger T. The cardiovascular continuum refined: A hypothesis. Blood pressure. Oct 2010;19(5):273-277.

11. Volpe M, McKelvie R, Drexler H. Hypertension as an underlying factor in heart failure with preserved ejection fraction. J Clin Hypertens (Greenwich). Apr 2010;12(4):277-283.

12. Macdougall IC, Canaud B, de Francisco AL, et al. Beyond the cardiorenal anaemia syndrome: recognizing the role of iron deficiency. Eur J Heart Fail. Aug 2012;14(8):882-886.

13. Taube A, Schlich R, Sell H, Eckardt K, Eckel J. Inflammation and metabolic dysfunction: links to cardiovascular diseases. Am J Physiol Heart Circ Physiol. Jun 1 2012;302(11):H2148-2165.

14. Donath MY, Shoelson SE. Type 2 diabetes as an inflammatory disease. Nat Rev Immunol. Feb 2011;11(2):98-107.

15. Szelenyi Z, Fazakas A, Szenasi G, et al. Inflammation and oxidative stress caused by nitric oxide synthase uncoupling might lead to left ventricular diastolic and systolic dysfunction in patients with hypertension. Journal of geriatric cardiology : JGC. Jan 2015;12(1):1-10. 
16. MacCarthy PA, Shah AM. Impaired endothelium-dependent regulation of ventricular relaxation in pressure-overload cardiac hypertrophy. Circulation. Apr 18 2000;101(15):1854-1860.

17. Yndestad A, Damas JK, Oie E, Ueland T, Gullestad L, Aukrust P. Systemic inflammation in heart failure--the whys and wherefores. Heart Fail Rev. Mar 2006;11(1):83-92.

18. Adamopoulos S, Parissis JT, Kremastinos DT. A glossary of circulating cytokines in chronic heart failure. Eur J Heart Fail. Oct 2001;3(5):517-526.

19. Heymans S, Hirsch E, Anker SD, et al. Inflammation as a therapeutic target in heart failure? A scientific statement from the Translational Research Committee of the Heart Failure Association of the European Society of Cardiology. Eur J Heart Fail. Feb 2009;11(2):119-129.

20. Mann DL. Targeted anticytokine therapy and the failing heart. Am J Cardiol. Jun 6 2005;95(11A):9C-16C; discussion 38C-40C.

21. Mann DL. Innate immunity and the failing heart: the cytokine hypothesis revisited. Circ Res. Mar 27 2015;116(7):1254-1268.

22. Chung ES, Packer M, Lo KH, Fasanmade AA, Willerson JT. Randomized, doubleblind, placebo-controlled, pilot trial of infliximab, a chimeric monoclonal antibody to tumor necrosis factor-alpha, in patients with moderate-to-severe heart failure: results of the anti-TNF Therapy Against Congestive Heart Failure (ATTACH) trial. Circulation. Jul 1 2003;107(25):3133-3140.

23. Torre-Amione G, Anker SD, Bourge RC, et al. Results of a non-specific immunomodulation therapy in chronic heart failure (ACCLAIM trial): a placebocontrolled randomised trial. Lancet. Jan 19 2008;371(9608):228-236. 
24. Ridker PM, Luscher TF. Anti-inflammatory therapies for cardiovascular disease. Eur Heart J. Jul 14 2014;35(27):1782-1791.

25. Lewinter C, Bland JM, Crouch S, et al. Impact of aspirin and statins on long-term survival in patients hospitalized with acute myocardial infarction complicated by heart failure: an analysis of 1706 patients. Eur J Heart Fail. Jan 2014;16(1):95-102.

26. Rogers JK, Jhund PS, Perez AC, et al. Effect of rosuvastatin on repeat heart failure hospitalizations: the CORONA Trial (Controlled Rosuvastatin Multinational Trial in Heart Failure). JACC. Heart failure. Jun 2014;2(3):289-297.

27. Westermann D, Riad A, Richter U, et al. Enhancement of the endothelial NO synthase attenuates experimental diastolic heart failure. Basic Res Cardiol. Sep 2009;104(5):499-509.

28. Flierl U, Fraccarollo D, Widder JD, et al. The nitric oxide donor pentaerythritol tetranitrate reduces platelet activation in congestive heart failure. PloS one. 2015;10(4):e0123621.

29. Yang Q, Xue HM, Wong WT, et al. AVE3085, an enhancer of endothelial nitric oxide synthase, restores endothelial function and reduces blood pressure in spontaneously hypertensive rats. Brit J Pharmacol. Jul 2011;163(5):1078-1085.

30. Frantz S, Adamek A, Fraccarollo D, et al. The eNOS enhancer AVE 9488: a novel cardioprotectant against ischemia reperfusion injury. Basic Research in Cardiology. Nov 2009;104(6):773-779.

31. Hood ED, Chorny M, Greineder CF, Alferiev IS, Levy RJ, Muzykantov VR. Endothelial targeting of nanocarriers loaded with antioxidant enzymes for protection against vascular oxidative stress and inflammation. Biomaterials. Apr 2014;35(11):3708-3715. 
32. Jia LX, Qi GM, Liu O, et al. Inhibition of platelet activation by clopidogrel prevents hypertension-induced cardiac inflammation and fibrosis. Cardiovasc Drugs Ther. Dec 2013;27(6):521-530.

33. Flierl U, Fraccarollo D, Micka J, Bauersachs J, Schafer A. The direct factor Xa inhibitor Rivaroxaban reduces platelet activation in congestive heart failure. Pharmacological research : the official journal of the Italian Pharmacological Society. Aug 2013;74:49-55.

34. Bermingham M, Shanahan MK, O'Connell E, et al. Aspirin use in heart failure: is low-dose therapy associated with mortality and morbidity benefits in a large community population? Circulation. Heart failure. Mar 1 2014;7(2):243-250.

35. Cleland JG, Parsons S. Aspirin for heart failure: theory- or evidence-based? Circulation. Heart failure. Mar 1 2014;7(2):237-238.

36. Homma S, Thompson JL, Pullicino PM, et al. Warfarin and aspirin in patients with heart failure and sinus rhythm. N Engl J Med. May 17 2012;366(20):1859-1869.

37. Fernandez-Velasco M, Gonzalez-Ramos S, Bosca L. Involvement of monocytes/macrophages as key factors in the development and progression of cardiovascular diseases. Biochem J. Mar 1 2014;458(2):187-193.

38. Rondina MT, Weyrich AS, Zimmerman GA. Platelets as cellular effectors of inflammation in vascular diseases. Circ Res. May 24 2013;112(11):1506-1519.

39. Schafer A, Eigenthaler M, Bauersachs J. Platelet activation in heart failure. Clinical laboratory. 2004;50(9-10):559-566.

40. Chung I, Lip GY. Platelets and heart failure. Eur Heart J. Nov 2006;27(22):26232631. 
41. Erne P, Wardle J, Sanders K, Lewis SM, Maseri A. Mean platelet volume and size distribution and their sensitivity to agonists in patients with coronary artery disease and congestive heart failure. Thromb Haemost. Apr 8 1988;59(2):259-263.

42. O'Connor CM, Gurbel PA, Serebruany VL. Usefulness of soluble and surface-bound P-selectin in detecting heightened platelet activity in patients with congestive heart failure. Am J Cardiol. May 1 1999;83(9):1345-1349.

43. Gibbs CR, Blann AD, Watson RD, Lip GY. Abnormalities of hemorheological, endothelial, and platelet function in patients with chronic heart failure in sinus rhythm: effects of angiotensin-converting enzyme inhibitor and beta-blocker therapy. Circulation. Apr 3 2001;103(13):1746-1751.

44. Yin WH, Chen JW, Jen HL, et al. The prognostic value of circulating soluble cell adhesion molecules in patients with chronic congestive heart failure. Eur J Heart Fail. Aug 2003;5(4):507-516.

45. Stumpf C, Lehner C, Eskafi S, et al. Enhanced levels of CD154 (CD40 ligand) on platelets in patients with chronic heart failure. Eur J Heart Fail. Oct 2003;5(5):629637.

46. Ueland T, Aukrust P, Yndestad A, et al. Soluble CD40 ligand in acute and chronic heart failure. Eur Heart J. Jun 2005;26(11):1101-1107.

47. Chung I, Choudhury A, Patel J, Lip GY. Soluble, platelet-bound, and total P-selectin as indices of platelet activation in congestive heart failure. Ann Med. 2009;41(1):4551.

48. Gurbel PA, Gattis WA, Fuzaylov SF, et al. Evaluation of platelets in heart failure: is platelet activity related to etiology, functional class, or clinical outcomes? Am Heart J. Jun 2002;143(6):1068-1075. 
49. Serebruany VL, Alford AB, Meister AF, et al. Clinical utility of the platelet function analyzer (PFA-100) for the assessment of the platelet status in patients with congestive heart failure (EPCOT trial). Thromb Res. Mar 15 2001;101(6):427-433.

50. Cleland JG, Findlay I, Jafri S, et al. The Warfarin/Aspirin Study in Heart failure (WASH): a randomized trial comparing antithrombotic strategies for patients with heart failure. Am Heart J. Jul 2004;148(1):157-164.

51. Massie BM, Collins JF, Ammon SE, et al. Randomized trial of warfarin, aspirin, and clopidogrel in patients with chronic heart failure: the Warfarin and Antiplatelet Therapy in Chronic Heart Failure (WATCH) trial. Circulation. Mar 31 2009;119(12):1616-1624.

52. Swirski FK, Nahrendorf M. Leukocyte behavior in atherosclerosis, myocardial infarction, and heart failure. Science. Jan 11 2013;339(6116):161-166.

53. Ghattas A, Griffiths HR, Devitt A, Lip GY, Shantsila E. Monocytes in coronary artery disease and atherosclerosis: where are we now? J Am Coll Cardiol. Oct 22 2013;62(17):1541-1551.

54. van Furth R, Cohn ZA. The origin and kinetics of mononuclear phagocytes. J Exp Med. Sep 1 1968;128(3):415-435.

55. Robbins CS, Chudnovskiy A, Rauch PJ, et al. Extramedullary hematopoiesis generates Ly-6C(high) monocytes that infiltrate atherosclerotic lesions. Circulation. Jan 17 2012;125(2):364-374.

56. Leuschner F, Rauch PJ, Ueno T, et al. Rapid monocyte kinetics in acute myocardial infarction are sustained by extramedullary monocytopoiesis. J Exp Med. Jan 16 2012;209(1):123-137. 
57. Apostolakis S, Lip GY, Shantsila E. Monocytes in heart failure: relationship to a deteriorating immune overreaction or a desperate attempt for tissue repair? Cardiovasc Res. Mar 1 2010;85(4):649-660.

58. Wrigley BJ, Lip GY, Shantsila E. The role of monocytes and inflammation in the pathophysiology of heart failure. Eur J Heart Fail. Nov 2011;13(11):1161-1171.

59. Kai H, Kuwahara F, Tokuda K, Imaizumi T. Diastolic dysfunction in hypertensive hearts: roles of perivascular inflammation and reactive myocardial fibrosis. Hypertens Res. Jun 2005;28(6):483-490.

60. Xia Y, Lee K, Li N, Corbett D, Mendoza L, Frangogiannis NG. Characterization of the inflammatory and fibrotic response in a mouse model of cardiac pressure overload. Histochem Cell Biol. Apr 2009;131(4):471-481.

61. Nicoletti A, Heudes D, Mandet C, Hinglais N, Bariety J, Michel JB. Inflammatory cells and myocardial fibrosis: spatial and temporal distribution in renovascular hypertensive rats. Cardiovasc Res. Dec 1996;32(6):1096-1107.

62. Jin RC, Voetsch B, Loscalzo J. Endogenous mechanisms of inhibition of platelet function. Microcirculation. Apr-May 2005;12(3):247-258.

63. Jennings LK. Mechanisms of platelet activation: need for new strategies to protect against platelet-mediated atherothrombosis. Thromb Haemost. Aug 2009;102(2):248257.

64. Davi G, Patrono C. Platelet activation and atherothrombosis. $N$ Engl J Med. Dec 13 2007;357(24):2482-2494.

65. van Gils JM, Zwaginga JJ, Hordijk PL. Molecular and functional interactions among monocytes, platelets, and endothelial cells and their relevance for cardiovascular diseases. J Leukoc Biol. Feb 2009;85(2):195-204. 
66. Varga-Szabo D, Pleines I, Nieswandt B. Cell adhesion mechanisms in platelets. Arterioscler Thromb Vasc Biol. Mar 2008;28(3):403-412.

67. Dorsam RT, Kunapuli SP. Central role of the P2Y12 receptor in platelet activation. $J$ Clin Invest. Feb 2004;113(3):340-345.

68. Showkathali R, Natarajan A. Antiplatelet and antithrombin strategies in acute coronary syndrome: state-of-the-art review. Curr Cardiol Rev. Aug 2012;8(3):239249.

69. Marnett LJ, Rowlinson SW, Goodwin DC, Kalgutkar AS, Lanzo CA. Arachidonic acid oxygenation by COX-1 and COX-2. Mechanisms of catalysis and inhibition. $J$ Biol Chem. Aug 13 1999;274(33):22903-22906.

70. Narumiya S. Prostanoid receptors. Structure, function, and distribution. Annals of the New York Academy of Sciences. Nov 15 1994;744:126-138.

71. Fontana P, Zufferey A, Daali Y, Reny JL. Antiplatelet therapy: targeting the TxA2 pathway. Journal of cardiovascular translational research. Feb 2014;7(1):29-38.

72. Fiessinger JN, Bounameaux H, Cairols MA, et al. Thromboxane Antagonism with terutroban in Peripheral Arterial Disease: the TAIPAD study. J Thromb Haemost. Nov 2010;8(11):2369-2376.

73. Neri Serneri GG, Coccheri S, Marubini E, Violi F. Picotamide, a combined inhibitor of thromboxane A2 synthase and receptor, reduces 2-year mortality in diabetics with peripheral arterial disease: the DAVID study. Eur Heart J. Oct 2004;25(20):18451852.

74. Rollini F, Tello-Montoliu A, Patel R, et al. Pharmacodynamic effects of EV-077 in patients with diabetes mellitus and coronary artery disease on aspirin or clopidogrel monotherapy: results of an in vitro pilot investigation. J Thromb Thrombolysis. 2014;37(2):131-138. 
75. Baigent C, Blackwell L, Collins R, et al. Aspirin in the primary and secondary prevention of vascular disease: collaborative meta-analysis of individual participant data from randomised trials. Lancet. May 30 2009;373(9678):1849-1860.

76. Randomized trial of ridogrel, a combined thromboxane A2 synthase inhibitor and thromboxane A2/prostaglandin endoperoxide receptor antagonist, versus aspirin as adjunct to thrombolysis in patients with acute myocardial infarction. The Ridogrel Versus Aspirin Patency Trial (RAPT). Circulation. Feb 1994;89(2):588-595.

77. Coughlin SR. Protease-activated receptors in hemostasis, thrombosis and vascular biology. J Thromb Haemost. Aug 2005;3(8):1800-1814.

78. Stone GW, McLaurin BT, Cox DA, et al. Bivalirudin for patients with acute coronary syndromes. N Engl J Med. Nov 23 2006;355(21):2203-2216.

79. Stone GW, Witzenbichler B, Guagliumi G, et al. Bivalirudin during primary PCI in acute myocardial infarction. N Engl J Med. May 22 2008;358(21):2218-2230.

80. Yusuf S, Mehta SR, Chrolavicius S, et al. Comparison of fondaparinux and enoxaparin in acute coronary syndromes. N Engl J Med. Apr 6 2006;354(14):14641476.

81. Yusuf S, Mehta SR, Chrolavicius S, et al. Effects of fondaparinux on mortality and reinfarction in patients with acute ST-segment elevation myocardial infarction: the OASIS-6 randomized trial. JAMA. Apr 5 2006;295(13):1519-1530.

82. Mega JL, Braunwald E, Wiviott SD, et al. Rivaroxaban in patients with a recent acute coronary syndrome. N Engl J Med. Jan 5 2012;366(1):9-19.

83. Alexander JH, Lopes RD, James S, et al. Apixaban with antiplatelet therapy after acute coronary syndrome. N Engl J Med. Aug 25 2011;365(8):699-708.

84. Tricoci P, Huang Z, Held C, et al. Thrombin-receptor antagonist vorapaxar in acute coronary syndromes. N Engl J Med. Jan 5 2012;366(1):20-33. 
85. Morrow DA, Braunwald E, Bonaca MP, et al. Vorapaxar in the secondary prevention of atherothrombotic events. N Engl J Med. Apr 12 2012;366(15):1404-1413.

86. Gordon S, Taylor PR. Monocyte and macrophage heterogeneity. Nat Rev Immunol. Dec 2005;5(12):953-964.

87. Kono H, Rock KL. How dying cells alert the immune system to danger. Nat Rev Immunol. Apr 2008;8(4):279-289.

88. Pamukcu B, Lip GY, Devitt A, Griffiths H, Shantsila E. The role of monocytes in atherosclerotic coronary artery disease. Ann Med. Sep 2010;42(6):394-403.

89. Maekawa Y, Anzai T, Yoshikawa T, et al. Prognostic significance of peripheral monocytosis after reperfused acute myocardial infarction:a possible role for left ventricular remodeling. J Am Coll Cardiol. Jan 16 2002;39(2):241-246.

90. Wang J, Zhang S, Jin Y, Qin G, Yu L, Zhang J. Elevated levels of platelet-monocyte aggregates and related circulating biomarkers in patients with acute coronary syndrome. Int J Cardiol. Feb 14 2007;115(3):361-365.

91. Tapp LD, Shantsila E, Wrigley BJ, Pamukcu B, Lip GY. The CD14++CD16+ monocyte subset and monocyte-platelet interactions in patients with ST-elevation myocardial infarction. J Thromb Haemost. Jul 2012;10(7):1231-1241.

92. Wrigley BJ, Shantsila E, Tapp LD, Lip GY. Increased formation of monocyte-platelet aggregates in ischemic heart failure. Circulation. Heart failure. Jan 2013;6(1):127135.

93. Damas JK, Gullestad L, Ueland T, et al. CXC-chemokines, a new group of cytokines in congestive heart failure--possible role of platelets and monocytes. Cardiovasc Res. Jan 14 2000;45(2):428-436.

94. Cosemans JM, Munnix IC, Wetzker R, Heller R, Jackson SP, Heemskerk JW. Continuous signaling via PI3K isoforms beta and gamma is required for platelet ADP 
receptor function in dynamic thrombus stabilization. Blood. Nov 1 2006;108(9):30453052.

95. Rinder HM, Bonan JL, Rinder CS, Ault KA, Smith BR. Dynamics of leukocyteplatelet adhesion in whole blood. Blood. Oct 1 1991;78(7):1730-1737.

96. da Costa Martins PA, van Gils JM, Mol A, Hordijk PL, Zwaginga JJ. Platelet binding to monocytes increases the adhesive properties of monocytes by up-regulating the expression and functionality of beta1 and beta2 integrins. J Leukoc Biol. Mar 2006;79(3):499-507.

97. Gawaz M, Neumann FJ, Dickfeld T, et al. Activated platelets induce monocyte chemotactic protein-1 secretion and surface expression of intercellular adhesion molecule-1 on endothelial cells. Circulation. Sep 22 1998;98(12):1164-1171.

98. Gawaz M, Langer H, May AE. Platelets in inflammation and atherogenesis. J Clin Invest. Dec 2005;115(12):3378-3384.

99. Mantovani A, Sica A, Sozzani S, Allavena P, Vecchi A, Locati M. The chemokine system in diverse forms of macrophage activation and polarization. Trends Immunol. Dec 2004;25(12):677-686.

100. Sica A, Mantovani A. Macrophage plasticity and polarization: in vivo veritas. J Clin Invest. Mar 1 2012;122(3):787-795.

101. Jungi TW, Spycher MO, Nydegger UE, Barandun S. Platelet-leukocyte interaction: selective binding of thrombin-stimulated platelets to human monocytes, polymorphonuclear leukocytes, and related cell lines. Blood. Mar 1986;67(3):629636.

102. Joseph JE, Harrison P, Mackie IJ, Isenberg DA, Machin SJ. Increased circulating platelet-leucocyte complexes and platelet activation in patients with antiphospholipid 
syndrome, systemic lupus erythematosus and rheumatoid arthritis. $\mathrm{Br} J$ Haematol. Nov 2001;115(2):451-459.

103. Michelson AD, Barnard MR, Krueger LA, Valeri CR, Furman MI. Circulating monocyte-platelet aggregates are a more sensitive marker of in vivo platelet activation than platelet surface P-selectin: studies in baboons, human coronary intervention, and human acute myocardial infarction. Circulation. Sep 25 2001;104(13):1533-1537.

104. Mickelson JK, Lakkis NM, Villarreal-Levy G, Hughes BJ, Smith CW. Leukocyte activation with platelet adhesion after coronary angioplasty: a mechanism for recurrent disease? J Am Coll Cardiol. Aug 1996;28(2):345-353.

105. Htun P, Fateh-Moghadam S, Tomandl B, et al. Course of platelet activation and platelet-leukocyte interaction in cerebrovascular ischemia. Stroke. Sep 2006;37(9):2283-2287.

106. Smout J, Dyker A, Cleanthis M, Ford G, Kesteven P, Stansby G. Platelet function following acute cerebral ischemia. Angiology. Jun-Jul 2009;60(3):362-369.

107. McCabe DJ, Harrison P, Mackie IJ, et al. Platelet degranulation and monocyteplatelet complex formation are increased in the acute and convalescent phases after ischaemic stroke or transient ischaemic attack. Br J Haematol. Jun 2004;125(6):777787.

108. Sarma J, Laan CA, Alam S, Jha A, Fox KA, Dransfield I. Increased platelet binding to circulating monocytes in acute coronary syndromes. Circulation. May 7 2002;105(18):2166-2171.

109. Furman MI, Benoit SE, Barnard MR, et al. Increased platelet reactivity and circulating monocyte-platelet aggregates in patients with stable coronary artery disease. J Am Coll Cardiol. Feb 1998;31(2):352-358. 
110. Rutten B, Tersteeg C, Vrijenhoek JE, et al. Increased platelet reactivity is associated with circulating platelet-monocyte complexes and macrophages in human atherosclerotic plaques. PloS one. 2014;9(8):e105019.

111. Shoji T, Koyama H, Fukumoto S, et al. Platelet activation is associated with hypoadiponectinemia and carotid atherosclerosis. Atherosclerosis. Sep 2006;188(1):190-195.

112. Gkaliagkousi E, Corrigall V, Becker S, et al. Decreased platelet nitric oxide contributes to increased circulating monocyte-platelet aggregates in hypertension. Eur Heart J. Dec 2009;30(24):3048-3054.

113. Harding SA, Sommerfield AJ, Sarma J, et al. Increased CD40 ligand and plateletmonocyte aggregates in patients with type 1 diabetes mellitus. Atherosclerosis. Oct 2004;176(2):321-325.

114. Rinder CS, Bonan JL, Rinder HM, Mathew J, Hines R, Smith BR. Cardiopulmonary bypass induces leukocyte-platelet adhesion. Blood. Mar 1 1992;79(5):1201-1205.

115. Martins Pda C, Zwaginga JJ. Leukocyte-platelet aggregates: new particles reflecting and effecting cardiovascular disease. Thromb Haemost. Dec 2005;94(6):1120-1121.

116. Aukrust $\mathrm{P}$, Ueland $\mathrm{T}$, Muller F, et al. Elevated circulating levels of $\mathrm{C}-\mathrm{C}$ chemokines in patients with congestive heart failure. Circulation. Mar 31 1998;97(12):1136-1143.

117. Glezeva N, Voon V, Watson C, et al. Exaggerated inflammation and monocytosis associate with diastolic dysfunction in heart failure with preserved ejection fraction: evidence of m2 macrophage activation in disease pathogenesis. J Card Fail. Feb 2015;21(2):167-177.

118. Neumann FJ, Marx N, Gawaz M, et al. Induction of cytokine expression in leukocytes by binding of thrombin-stimulated platelets. Circulation. May 20 1997;95(10):23872394. 
119. Passacquale G, Vamadevan P, Pereira L, Hamid C, Corrigall V, Ferro A. Monocyteplatelet interaction induces a pro-inflammatory phenotype in circulating monocytes. PloS one. 2011;6(10):e25595.

120. Li N, Hu H, Lindqvist M, Wikstrom-Jonsson E, Goodall AH, Hjemdahl P. Plateletleukocyte cross talk in whole blood. Arterioscler Thromb Vasc Biol. Dec 2000;20(12):2702-2708.

121. Huo Y, Schober A, Forlow SB, et al. Circulating activated platelets exacerbate atherosclerosis in mice deficient in apolipoprotein E. Nature medicine. Jan 2003;9(1):61-67.

122. Fernandes LS, Conde ID, Wayne Smith C, et al. Platelet-monocyte complex formation: effect of blocking PSGL-1 alone, and in combination with alphaIIbbeta3 and alphaMbeta2, in coronary stenting. Thromb Res. 2003;111(3):171-177.

123. van Gils JM, da Costa Martins PA, Mol A, Hordijk PL, Zwaginga JJ. Transendothelial migration drives dissociation of plateletmonocyte complexes. Thromb Haemost. Aug 2008;100(2):271-279.

124. Cokkinos DV, Haralabopoulos GC, Kostis JB, Toutouzas PK. Efficacy of antithrombotic therapy in chronic heart failure: the HELAS study. Eur J Heart Fail. Jun 2006;8(4):428-432.

125. Gullestad L, Ueland T, Fjeld JG, et al. Effect of thalidomide on cardiac remodeling in chronic heart failure: results of a double-blind, placebo-controlled study. Circulation. Nov 29 2005;112(22):3408-3414.

126. Gullestad L, Aass H, Fjeld JG, et al. Immunomodulating therapy with intravenous immunoglobulin in patients with chronic heart failure. Circulation. Jan 16 2001;103(2):220-225. 
127. Van Tassell BW, Arena R, Biondi-Zoccai G, et al. Effects of interleukin-1 blockade with anakinra on aerobic exercise capacity in patients with heart failure and preserved ejection fraction (from the D-HART pilot study). Am J Cardiol. Jan 15 2014;113(2):321-327.

128. Kalogeropoulos A, Georgiopoulou V, Psaty BM, et al. Inflammatory markers and incident heart failure risk in older adults: the Health ABC (Health, Aging, and Body Composition) study. J Am Coll Cardiol. May 11 2010;55(19):2129-2137.

129. Juhlin T, Jonsson BA, Hoglund P. Renal effects of aspirin are clearly dose-dependent and are of clinical importance from a dose of $160 \mathrm{mg}$. Eur J Heart Fail. Sep 2008;10(9):892-898.

130. Medina C, Harmon S, Inkielewicz I, et al. Differential inhibition of tumour cellinduced platelet aggregation by the nicotinate aspirin prodrug (ST0702) and aspirin. Br J Pharmacol. Jun 2012;166(3):938-949.

131. Weber KT, Janicki JS, Shroff SG, Pick R, Chen RM, Bashey RI. Collagen remodeling of the pressure-overloaded, hypertrophied nonhuman primate myocardium. Circ Res. Apr 1988;62(4):757-765.

132. Boluyt $\mathrm{MO}$, Bing $\mathrm{OH}$. Matrix gene expression and decompensated heart failure: the aged SHR model. Cardiovasc Res. May 2000;46(2):239-249.

133. Dai Z, Aoki T, Fukumoto Y, Shimokawa H. Coronary perivascular fibrosis is associated with impairment of coronary blood flow in patients with non-ischemic heart failure. J Cardiol. Nov 2012;60(5):416-421.

134. Futh R, Dinh W, Nickl W, et al. Soluble P-selectin and matrix metalloproteinase 2 levels are elevated in patients with diastolic dysfunction independent of glucose metabolism disorder or coronary artery disease. Experimental and clinical cardiology. Fall 2009;14(3):e76-79. 
135. Chen WS, Chen SJ, Lee CC, Cherng WJ, Liu MH, Wang CH. Plasma P-selectin predicts long-term cardiovascular events in hospitalized patients with suspected coronary artery disease and preserved left ventricular function: a 10-year follow-up study. Biomedical journal. May-Jun 2013;36(3):137-143.

136. Graciano AL, Bryant DD, White DJ, Horton J, Bowles NE, Giroir BP. Targeted disruption of ICAM-1, P-selectin genes improves cardiac function and survival in TNF-alpha transgenic mice. Am J Physiol Heart Circ Physiol. Apr 2001;280(4):H1464-1471.

137. Moertl D, Berger R, Hammer A, et al. Dose-dependent decrease of platelet activation and tissue factor by omega-3 polyunsaturated fatty acids in patients with advanced chronic heart failure. Thromb Haemost. Sep 2011;106(3):457-465.

138. Bjornstad HH, Bruvik J, Bjornstad AB, Hjellestad BL, Damas JK, Aukrust P. Exercise training decreases plasma levels of soluble CD40 ligand and P-selectin in patients with chronic heart failure. European journal of cardiovascular prevention and rehabilitation : official journal of the European Society of Cardiology, Working Groups on Epidemiology \& Prevention and Cardiac Rehabilitation and Exercise Physiology. Feb 2008;15(1):43-48.

139. Serebruany VL, Malinin AI, Jerome SD, et al. Effects of clopidogrel and aspirin combination versus aspirin alone on platelet aggregation and major receptor expression in patients with heart failure: the Plavix Use for Treatment Of Congestive Heart Failure (PLUTO-CHF) trial. Am Heart J. Oct 2003;146(4):713-720.

140. Malinin AI, Oshrine BR, Sane DC, O'Connor CM, Serebruany VL. Does heart failure etiology, New York Heart Association class, or ejection fraction affect the ability of clopidogrel to inhibit heightened platelet activity? Blood coagulation \& fibrinolysis : an international journal in haemostasis and thrombosis. Mar 2007;18(2):91-96. 
141. Serebruany VL, Glassman AH, Malinin AI, et al. Selective serotonin reuptake inhibitors yield additional antiplatelet protection in patients with congestive heart failure treated with antecedent aspirin. Eur J Heart Fail. Aug 2003;5(4):517-521.

142. Gheorghiade M, Thyssen A, Zolynas R, et al. Pharmacokinetics and pharmacodynamics of rivaroxaban and its effect on biomarkers of hypercoagulability in patients with chronic heart failure. The Journal of heart and lung transplantation : the official publication of the International Society for Heart Transplantation. Feb 2011;30(2):218-226.

143. Cugno M, Mari D, Meroni PL, et al. Haemostatic and inflammatory biomarkers in advanced chronic heart failure: role of oral anticoagulants and successful heart transplantation. Br J Haematol. Jul 2004;126(1):85-92.

144. Mann DL, McMurray JJ, Packer M, et al. Targeted anticytokine therapy in patients with chronic heart failure: results of the Randomized Etanercept Worldwide Evaluation (RENEWAL). Circulation. Apr 6 2004;109(13):1594-1602. 


\section{Tables}

Table 1 Clinical trials in Heart Failure with Preserved and Reduced Ejection Fraction utilizing anti-platelet and anti-inflammatory therapies

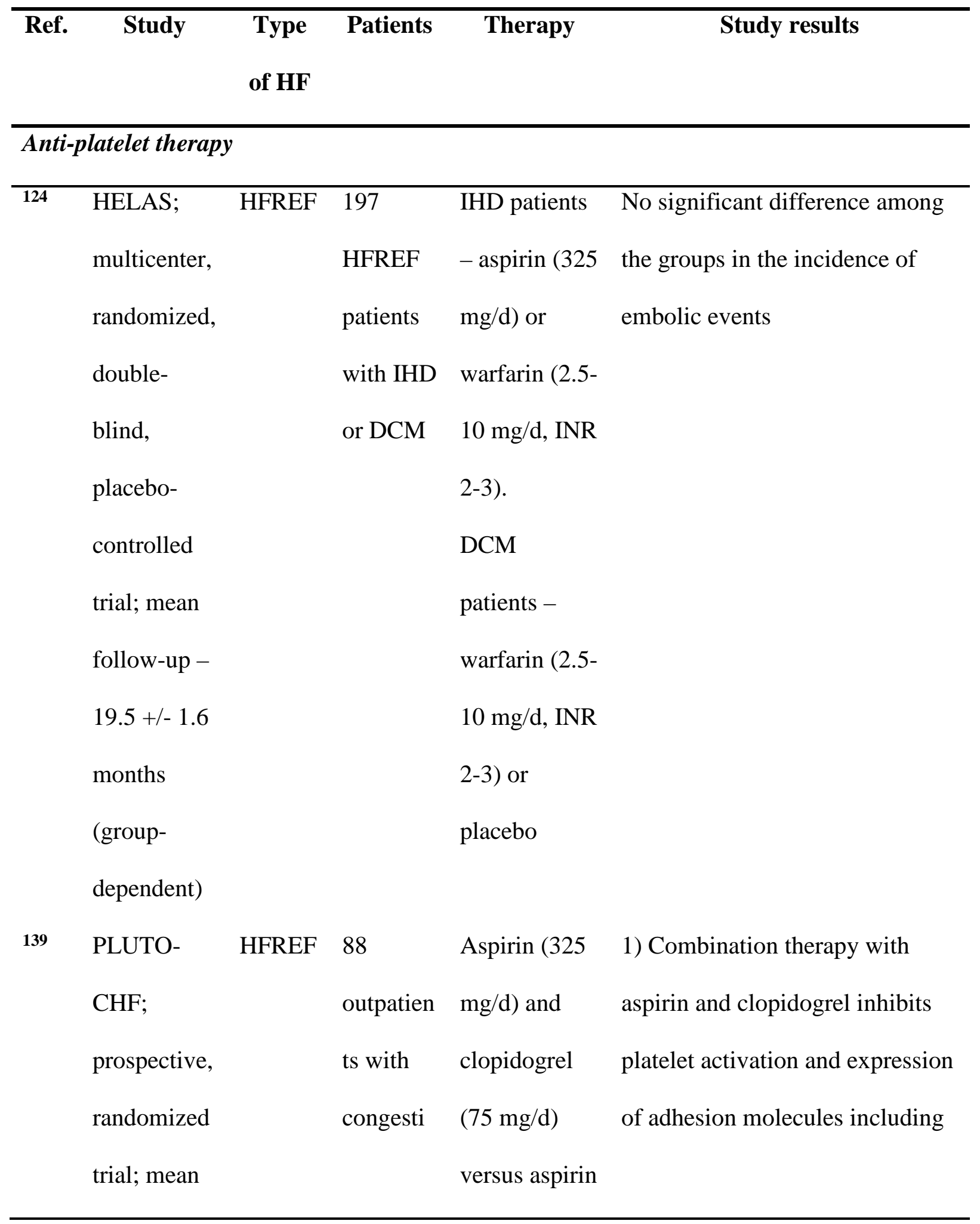




\begin{tabular}{|c|c|c|c|c|c|}
\hline & follow-up - & & ve & $(325 \mathrm{mg} / \mathrm{d})$ & P-selectin when compared with \\
\hline & 1 month & & HFREF & alone & aspirin alone therapy \\
\hline \multirow[t]{8}{*}{50} & WASH; & HFREF & 279 & Aspirin (300 & 1) No difference in primary \\
\hline & open-label, & & patients & $\mathrm{mg} / \mathrm{d}) \mathrm{vs}$. & clinical outcome (death, nonfatal \\
\hline & randomized, & & with & warfarin & MI, or nonfatal stroke) between \\
\hline & controlled & & HFREF & (INR 2.5) vs. & aspirin, warfarin or non-treated \\
\hline & trial; mean & & in sinus & no therapy & group \\
\hline & follow-up - & & rhythm & & 2) Increased risk of all cause \\
\hline & $27+/-1$ & & & & (re)hospitalization (secondary \\
\hline & months & & & & endpoint) in aspirin group \\
\hline \multirow[t]{12}{*}{51} & WATCH; & HFREF & 1587 & Double-blind & 1) All 3 drugs have equal \\
\hline & multination & & patients & aspirin (162 & beneficial effects with respect to \\
\hline & al, & & with & $\mathrm{mg} / \mathrm{d})$ or & primary end point (reduced all- \\
\hline & prospective, & & HFREF & clopidogrel & cause mortality, nonfatal MI, and \\
\hline & randomized & & in sinus & (75 mg/d) vs. & nonfatal stroke) \\
\hline & trial; mean & & rhythm & open-label & 2) Warfarin is superior to aspirin \\
\hline & follow-up - & & & warfarin & and clopidogrel in reducing \\
\hline & 1.9 yrs. & & & (INR 2.5-3.0) & secondary endpoints (non-fatal \\
\hline & & & & & stroke and (re)hospitalizations \\
\hline & & & & & due to worsening $\mathrm{HF}$ ), but \\
\hline & & & & & associates with increased risk of \\
\hline & & & & & minor bleeding \\
\hline \multirow[t]{3}{*}{36} & WARCEF; & HFREF & 2305 & Aspirin (325 & 1) Similar beneficial effect with \\
\hline & double- & & patients & $\mathrm{mg} / \mathrm{d}) \mathrm{vs}$. & either drug on primary outcome \\
\hline & blind, & & with & warfarin & \\
\hline
\end{tabular}




\begin{tabular}{|c|c|c|c|c|c|}
\hline & multicenter & & HFREF & (INR 2.0-3.5) & (ischemic stroke, intracerebral \\
\hline & trial; mean & & in sinus & & hemorrhage, or all-cause death) \\
\hline & follow-up - & & rhythm & & 2) No difference in primary \\
\hline & $3.5 \pm 1.8$ yrs. & & & & outcome between treatment with \\
\hline & & & & & warfarin or aspirin \\
\hline & & & & & 3) reduced risk of ischemic \\
\hline & & & & & stroke with warfarin, offset by an \\
\hline & & & & & increased risk of major \\
\hline & & & & & hemorrhage \\
\hline & & & & & 4) a trend toward an increased \\
\hline & & & & & rate of hospitalization for heart \\
\hline & & & & & failure in the warfarin group, in \\
\hline & & & & & direct contrast to the results of \\
\hline & & & & & the WASH and WATCH trials \\
\hline 34 & Observation & HFREF & 1476 & low-dose & 1) low-dose aspirin associates \\
\hline & al & and & patients & aspirin $(75$ & with reduced mortality risk \\
\hline & retrospectiv & HFPEF & with HF & $\mathrm{mg} / \mathrm{d}) \mathrm{vs}$. & (primary endpoint) compared \\
\hline & e & & comorbi & non-aspirin & with non-aspirin use \\
\hline & community- & & dities & and high- & 2) low-dose aspirin associates \\
\hline & based study; & & attending & dose aspirin & with reduced risk of HF \\
\hline & median & & a HF & $(>75 \mathrm{mg} / \mathrm{d})$ & hospitalization (secondary \\
\hline & follow-up - & & disease & & endpoint) compared with non- \\
\hline & $2.6(0.8-4.5)$ & & manage & & aspirin use in the total population \\
\hline & yrs. & & ment & & 3) no difference in mortality or \\
\hline & & & program & & HF hospitalization between high- \\
\hline
\end{tabular}


and non-aspirin users

\begin{tabular}{|c|c|c|c|c|c|}
\hline \multicolumn{6}{|c|}{ Anti- inflammatory therapy } \\
\hline \multirow[t]{12}{*}{128} & Health & HFPEF & 2610 & Standard & 1) Strong association of \\
\hline & $\mathrm{ABC}$; & and & (older) & anti- & inflammatory markers (IL6, \\
\hline & observation & HFREF & patients & hypertensive, & TNF $\alpha$, CRP) with HF - \\
\hline & al & & with HF & antithromboti & particularly HFPEF - risk \\
\hline & community- & & comorbi & c, and anti- & 2) Monitoring of and intervention \\
\hline & based study; & & dities & inflammatory & with inflammatory markers may \\
\hline & median & & attending & HF therapy & improve risk stratification and \\
\hline & follow-up - & & a HF & & reduce mortality in HFPEF \\
\hline & 9.4 yrs. & & disease & & \\
\hline & & & manage & & \\
\hline & & & ment & & \\
\hline & & & program & & \\
\hline \multirow[t]{10}{*}{144} & RENEWAL & HFREF & 1123 & Etanercept & 1) The TNF $\alpha$ inhibitor etanercept \\
\hline & (including & & patients & $(25 \mathrm{mg} / 2 \mathrm{x}$ & had no effect on clinical status at \\
\hline & RENAISSA & & (RENAI & week) vs. & 24 weeks (primary endpoint) in \\
\hline & NCE and & & SSANC & etanercept & RENAISSANCE or RECOVER \\
\hline & RECOVER) & & E) and & $(25 \mathrm{mg} / 3 \mathrm{x}$ & 2) Etarnecept had no effect on \\
\hline & ; double- & & 925 & week) vs. & the death or chronic HF \\
\hline & blind, & & patients & placebo & hospitalization end point in \\
\hline & randomized, & & (RECOV & (RENAISSA & RENEWAL \\
\hline & placebo- & & ER) with & $\mathrm{NCE})$ & \\
\hline & controlled & & moderate & & \\
\hline
\end{tabular}




\begin{tabular}{|c|c|c|c|c|c|}
\hline & multicenter & & to severe & Etanercept & \\
\hline & trial; mean & & HFREF & (25 mg/ & \\
\hline & follow-up - & & & week) vs. & \\
\hline & 24 weeks & & & etanercept & \\
\hline & & & & $(25 \mathrm{mg} / 2 \mathrm{x}$ & \\
\hline & & & & week) vs. & \\
\hline & & & & placebo & \\
\hline & & & & (RECOVER) & \\
\hline 22 & ATTACH; & HFREF & 150 & Infliximab (5 & 1) Neither dose of the TNF $\alpha$ \\
\hline & randomized, & & patients & $\mathrm{mg} / \mathrm{kg}) \mathrm{vs}$. & inhibitor infliximab improved \\
\hline & double- & & with & infliximab & clinical status at 14 weeks \\
\hline & blind, & & moderate & (10 mg/kg) & (primary endpoint) despite \\
\hline & placebo- & & to severe & vs. placebo at & suppression of inflammatory \\
\hline & controlled & & HFREF & 0,2 , and 6 & markers and a modest increase in \\
\hline & trial; mean & & & weeks after & ejection fraction \\
\hline & follow-up - & & & randomizatio & 2) Significant increase in death \\
\hline & 28 weeks & & & $\mathrm{n}$ & and HF hospitalization at 28 \\
\hline & & & & & weeks in the patients who \\
\hline & & & & & received $10 \mathrm{mg} / \mathrm{kg}$ infliximab \\
\hline 23 & ACCLAIM; & HFREF & 2426 & non-specific & 1) IMT was associated with a \\
\hline & double- & & patients & immunomod & significant reduction in the risk \\
\hline & blind, & & with & ulation & of primary endpoint events \\
\hline & placebo- & & HFREF & therapy & (composite of time to death from \\
\hline & controlled & & and $\mathrm{HF}$ & (IMT) & any cause or first hospitalization \\
\hline & randomized & & hospitali & & for cardiovascular reason) \\
\hline
\end{tabular}




\begin{tabular}{|c|c|c|c|c|c|}
\hline & trial; mean & & zation or & vs. placebo & 2) Such benefits were seen also \\
\hline & follow-up - & & iv drug & by & in patients without a history of \\
\hline & 10.2 months & & therapy & intragluteal & MI (irrespective of NYHA) and \\
\hline & & & in an & injection on & patients within NYHAII. \\
\hline & & & outpatien & days $1,2,14$, & \\
\hline & & & t setting & and every 28 & \\
\hline & & & within & days & \\
\hline & & & the past & thereafter & \\
\hline & & & 12 & & \\
\hline & & & months & & \\
\hline 125 & Double- & HFREF & 56 & Thalidomide & 1) The TNF $\alpha$ antagonist \\
\hline & blind, & & patients & (25 mg QD & thalidomide significantly \\
\hline & placebo- & & with & increasing to & improved cardiac function \\
\hline & controlled & & HFREF & 200 mg QD) & (LVEF, in LV end-diastolic \\
\hline & randomized & & secondar & vs. placebo & volume, heart rate) and improved \\
\hline & trial; mean & & $\mathrm{y}$ to & for 12 weeks & matrix-stabilization by \\
\hline & follow-up - & & IDCM or & & decreasing matrix \\
\hline & 12 weeks & & CAD & & metalloproteinase-2 (with no \\
\hline & & & & & change in its inhibitor). These \\
\hline & & & & & effects on LVEF were more \\
\hline & & & & & marked in IDCM than in CAD \\
\hline & & & & & 2) Thalidomide had both pro- and \\
\hline & & & & & anti-inflammatory effects (lower \\
\hline & & & & & total neutrophil count, higher \\
\hline & & & & & $\mathrm{TNF} \alpha$ \\
\hline
\end{tabular}




\begin{tabular}{|c|c|c|c|c|c|}
\hline \multirow[t]{11}{*}{126} & Double- & HFREF & 40 & Intravenous & 1) IVIG increased anti- \\
\hline & blind, & & patients & immunoglob & inflammatory mediators (IL10, \\
\hline & placebo- & & with & ulin (IVIG) & IL1 receptor antagonist, soluble \\
\hline & controlled & & HFREF & vs. placebo & TNF receptors) and decreased N- \\
\hline & randomized & & stratified & for 26 weeks & terminal pro-atrial natriuretic \\
\hline & trial; mean & & accordin & & peptide favoring a net anti- \\
\hline & follow-up - & & $\mathrm{g}$ to & & inflammatory effect in HFREF \\
\hline & 26 weeks & & cause & & 2) IVIG significantly improved \\
\hline & & & (ICM & & LVEF, independent of the cause \\
\hline & & & and & & of $\mathrm{HF}$ \\
\hline & & & IDCM) & & \\
\hline \multirow[t]{12}{*}{127} & D-HART; & HFPEF & 12 & Anakinra & 1) IL1 receptor blockade with \\
\hline & double- & & patients & (100 mg) or & anakinra significantly improved \\
\hline & blind, & & with & placebo) for & peak oxygen consumption \\
\hline & randomized, & & HFPEF & 14 days and & (aerobic exercise capacity) and \\
\hline & placebo- & & $(\mathrm{LVEF} \geq$ & an additional & reduced plasma CRP (systemic \\
\hline & controlled, & & $50 \%)$ & 14 days of & inflammation) from baseline to \\
\hline & crossover & & and & the alternate & the post-treatment follow-up \\
\hline & trial; mean & & evidence & treatment & point (primary endpoint). \\
\hline & follow-up - & & of & (placebo or & 2) CRP reduction correlated with \\
\hline & 28 days & & systemic & anakinra) & the improvement in peak oxygen \\
\hline & & & inflamm & & consumption (secondary \\
\hline & & & ation & & endpoint). \\
\hline
\end{tabular}

INR, international normalized ratio; iv, intravenous; IDCM, idiopathic dilated cardiomyopathy; DCM, dilated cardiomyopathy; CAD, coronary artery disease; ICM, ischemic cardiomyopathy; IHD, ischemic heart disease 


\section{Figure legends}

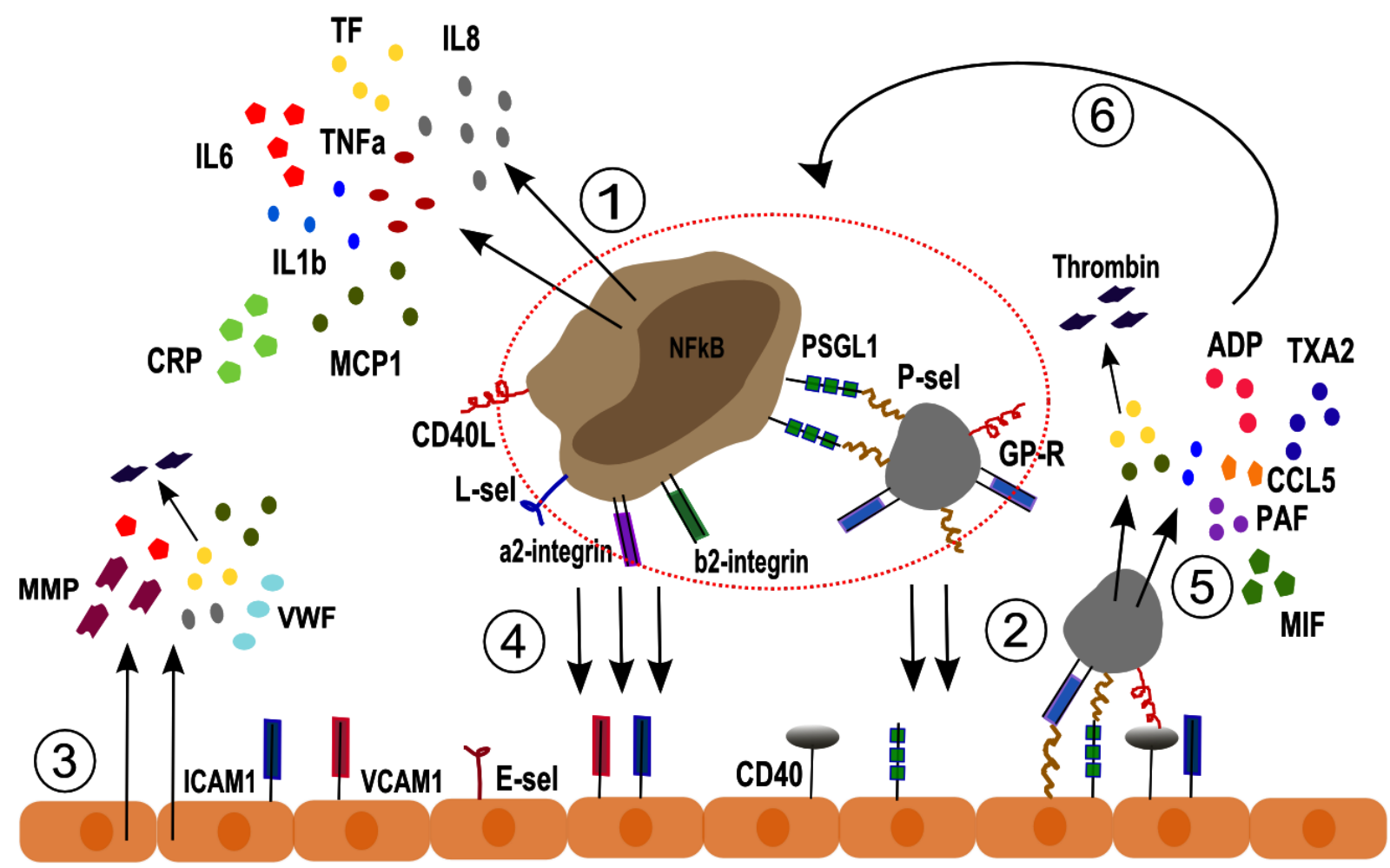

Figure 1 The monocyte - platelet - endothelial cell communication network. (1)

Pathophysiological signals promote monocyte and platelet activation in the blood. Cell activation results in release of inflammatory mediators (IL1 $\beta$, TNF $\alpha$, IL6, IL8, MCP1, CRP, TF) and upregulation of adhesion molecules (P-sel, L-sel, CD40L, $\alpha / \beta$-integrins, GP-R) in both monocytes and platelets, however with major contribution of monocytes. These aid monocyte - platelet interactions and formation of complexes (mainly in a P-selectin PSGL1). Subsequent events include (2) platelet adhesion to the endothelium, (3) expression of adhesion (PSGL1, CD40, E-sel, ICAM1, VCAM1) and inflammatory (MMP, MCP1, VWF, IL6, IL8, TF, thrombin) mediators from activated endothelium, and (4) recruitment, adhesion and transmigration of monocytes across the endothelium. The precise order of the latter three events is unclear as they may happen simultaneously and each one may precede 
another of happen as a result of it. In either case, (5) endothelium-adherent platelets secrete an array of inflammatory chemokines and mediators (ADP, TXA2, PAF, TF, thrombin, MCP1, IL1 $\beta$, MIF, CCL5) aimed at recruitment and adhesion of more platelets (in physiological and pathological thrombus formation) and recruitment and activation of monocytes, which (6) back-loops to further boost monocyte - platelet interactions. 